(C) 2021, The Authors. Published by Elsevier Inc. and Fass Inc. on behalf of the American Dairy Science Association ${ }^{\circledR}$. This is an open access article under the CC BY-NC-ND license (http://creativecommons.org/licenses/by-nc-nd/4.0/).

\title{
Differences in net fat oxidation, heat production, and liver mitochondrial DNA copy numbers between high and low feed-efficient dairy cows
}

\author{
K. M. Kennedy, ${ }^{1} \odot$ F. Becker, ${ }^{2}$ H. M. Hammon, ${ }^{2}{ }^{\oplus}$ and B. Kuhla ${ }^{1 *} \odot$ \\ ${ }^{1}$ Institute for Farm Animal Biology (FBN), Institute of Nutritional Physiology "Oskar Kellner," Dummerstorf 18196, Germany \\ ${ }^{2}$ Institute for Farm Animal Biology (FBN), Institute of Reproductive Biology, Dummerstorf 18196, Germany
}

\begin{abstract}
Improving feed utilization efficiency in dairy cattle could have positive economic and environmental effects that would support the sustainability of the dairy industry. Identifying key differences in metabolism between high and low feed-efficient animals is vital to enhancing feed conversion efficiency. Therefore, our objectives were (1) to determine whether cows grouped by either high or low feed efficiency have measurable differences in net fat and carbohydrate metabolism that account for differences in heat production (HP), and if so, whether these differences also exists under conditions of feed withdrawal when the effect of feeding on HP is minimized, and (2) to determine whether the abundance of mitochondria in the liver can be related to the high or low feed-efficient groups. Ten dairy cows from a herd of 15 (parity $=2$ ) were retrospectively grouped into either a high $(\mathrm{H})$ or a low $(\mathrm{L})$ feed-efficient group $(\mathrm{n}=5$ per group) based on weekly energy-corrected milk (ECM) divided by dry mater intake (DMI) from wk 4 through 30 of lactation. Livers were biopsied at wk $-4,2$, and 12 , and blood was sampled weekly from wk -3 to 12 relative to parturition. Blood was subset to be analyzed for the transition period (wk -3 to 3 ) and from wk 4 to 12 . In wk $5.70 \pm 0.82$ (mean $\pm \mathrm{SD}$ ) postpartum (PP), cows spent $2 \mathrm{~d}$ in respiration chambers (RC), in which $\mathrm{CO}_{2}, \mathrm{O}_{2}$, and $\mathrm{CH}_{4}$ gases were measured every 6 min for 24 h. Fatty acid oxidation (FOX), carbohydrate oxidation (COX), metabolic respiratory quotient (RQ), and HP were calculated from gas measurements for $23 \mathrm{~h}$. Cows were fed ad libitum (AD-LIB) on d 1 and had feed withdrawn (RES, restricted diet) on d 2. Additional blood samples were taken at the end of the AD-LIB and RES feeding periods in the RC. During wk 4 to $30 \mathrm{PP}, \mathrm{H}$ had greater $\mathrm{DMI} / \mathrm{kg}$ of metabolic body weight $\left(\mathrm{BW}^{0.75}\right)$, ECM per kilogram of $\mathrm{BW}^{0.75}$ yield, and $\mathrm{ECM} / \mathrm{DMI}$ ratio, compared with $\mathrm{L}$, but a lower
\end{abstract}

\footnotetext{
Received December 11, 2020

Accepted March 18, 2021

*Corresponding author: b.kuhla@fbn-dummerstorf.de
}

body condition score between wk 4 and $12 \mathrm{PP}$. In the $\mathrm{RC}$ period, we detected no differences in BW, DMI, or milk yield between groups. We also detected no significant group or group by feeding period interactions for plasma metabolites except for Revised Quantitative Insulin Sensitivity Check Index, which tended to have a group by feeding period interaction. The $\mathrm{H}$ group had lower HP and HP per kilogram of $\mathrm{BW}^{0.75}$ compared with L. Additionally, $\mathrm{H}$ had lower FOX and FOX per kilogram of $\mathrm{BW}^{0.75}$ compared with $\mathrm{L}$ during the AD-LIB period. Methane, $\mathrm{CH}_{4}$ per kilogram of $\mathrm{BW}^{0.75}$, and $\mathrm{CH}_{4}$ per kilogram of milk yield were lower in $\mathrm{H}$ compared with L, but, when adjusted for DMI, $\mathrm{CH}_{4}$ / DMI did not differ between groups, nor did HP/DMI. Relative mitochondrial DNA copy numbers in the liver were lower in the $\mathrm{L}$ than in the $\mathrm{H}$ group. These results suggest that lower feed efficiency in dairy cows may result from fewer mitochondria per liver cell as well as a greater whole-body HP, which likely partially results from higher net fat oxidation.

Key words: dairy cows, heat production, efficiency

\section{INTRODUCTION}

With increasing economic and environmental concerns, optimizing dairy cattle management in a sustainable manner is vital for the industry. A target for increasing sustainability is improving feed efficiency in dairy cows such that dairy cows produce milk at current production levels but use less feed, or conversely, produce more milk at current feed intake, while maintaining good health. Partitioning feed more effectively toward production and less toward waste is assumed to have positive economic and environmental impacts ( $\mathrm{Li}$ et al., 2019; Guinguina et al., 2020). Improving production efficiency has been a focus in dairy cattle for many years, and previous research, as well as potential areas for improvement, have previously been summarized in review articles (Bauman et al., 1985; Drackley et al., 2006). Feed efficiency is typically defined as either feed conversion efficiency (ECM/DMI) or residual feed intake (RFI). The feed conversion efficiency is the ratio 
of ECM produced per kilogram of DM consumed by a dairy cow. Conversely, RFI is described as the difference between actual and expected feed intake, and typically accounts for energy sinks such as ECM and BW changes (Guinguina et al., 2020). A negative or low RFI indicates an animal that consumes less feed than expected (i.e., more efficient) whereas a positive or high RFI indicates an animal that consumes more feed than expected (i.e., less efficient). Much of the research in RFI of ruminants has been focused on beef cattle, but research investigating RFI in dairy cattle is increasing due to its potential as a trait for genetic selection ( $\mathrm{Li}$ et al., 2019).

In beef cattle, a review by Cantalapiedra-Hijar et al. (2018) suggested that higher feed-efficient animals exhibit lower maintenance energy requirements and potentially a higher efficiency of ME utilization toward growth. Typically, the major factors thought to affect basal maintenance expenditures consist of protein turnover, tissue metabolism, cellular energy expenditures such as the $\mathrm{Na}^{+} / \mathrm{K}^{+}$ion pump, and proton leakage (Cantalapiedra-Hijar et al., 2018). The theory for suspecting differences in maintenance is due to repeatedly noted differences in heat production (HP) between high and low feed-efficient animals, such that highly efficient animals generally produce less heat (Basarab et al., 2003; Nkrumah et al., 2006; Cantalapiedra-Hijar et al., 2018).

The vast majority of cellular energy is produced from the oxidation of either carbohydrates, fats, or protein. Based on the stoichiometry of those oxidation equations and energy values associated with these metabolic fuels, we are able to estimate the net disappearance of metabolic fuels used for oxidation based on $\mathrm{O}_{2}$ and $\mathrm{CO}_{2}$ levels using indirect calorimetry (Frayn, 1983; Derno et al., 2013). However, the extent of HP from each metabolic fuel is dependent on other factors, such as the number of mitochondria per cell, coupling efficiency of the mitochondrial electron transport chain, anaerobic pathways, and proton leakage. These factors also account for the efficiency of ATP production, but because the latter is difficult to measure, the plasma kynurenine/tryptophan ratio has been suggested as a suitable marker for mitochondrial activity and ATP production efficiency (Lindquist et al., 2020). Past research has used genomics and proteomics to identify areas that may influence RFI and, hence, efficiency (Alexandre et al., 2015; Tizioto et al., 2015; Li et al., 2019). Additionally, other research has focused on identifying differences in mitochondrial function within specific tissues of animals grouped by efficiency (Kolath et al., 2006b; Lancaster et al., 2014; Fonseca et al., 2015). From this and other research, it has been suggested that lipid metabolism and the abundance of mitochondria per cell may be altered in low efficient animals compared with high efficient animals (Alexandre et al., 2015; Tizioto et al., 2015; Cantalapiedra-Hijar et al., 2018). Nevertheless, to our knowledge, whole-body fuel oxidation preferences have not been evaluated in dairy cows grouped by feed efficiency.

Our primary objective was to determine whether cows grouped by either high or low feed efficiency have measurable differences in net fat and carbohydrate metabolism that account for differences in heat production and, if so, whether these differences also exists under conditions of feed withdrawal when the effect of feeding on HP is minimized. Our secondary objective was to determine whether the abundance of mitochondria in the liver can be related to the high or low feed-efficient groups. We hypothesized that cows with a higher feed efficiency will have more mitochondria per cell and increased net carbohydrate oxidation (COX) but less net fatty acid oxidation (FOX) and HP compared with cows with a lower feed efficiency, regardless of nutritional status.

\section{MATERIALS AND METHODS}

\section{Experimental Design and Animal Management}

The experimental protocol was approved by the local animal ethics committee (Landesamt für Landwirtschaft, Lebensmittelsicherheit und Fischerei Mecklenburg-Vorpommern; approval no. 7221.3-1-016/18). A herd of 15 German Holstein dairy cows (parity = 2) were observed from wk -3 to 30 of lactation. From this herd, 1 cow was removed due to faulty respiration chamber (RC) data, and 3 cows were removed due to high plasma creatine kinase concentration $(>900 \mathrm{U} / \mathrm{L})$ during the RC period, which may indicate that the animal is undergoing stress or illness that could bias the data. Of the remaining 11 cows, the 10 most extreme cows were retrospectively grouped into either a high $(\mathbf{H} ; \mathrm{n}=5)$ or a low $(\mathbf{L} ; \mathrm{n}=5)$ feed efficiency group, determined by weekly ECM/DMI from wk 4 through 30 of lactation. Cows in the first 3 to 4 wk of lactation increasingly use fatty acids as a fuel, and the extent of fat mobilization has been found to be directly related to fat oxidation in early lactation (Börner et al., 2013). Thus, we chose to focus our study and grouping beginning at wk 4 to minimize interindividual differences in fat mobilization. However, some key markers related to fatty acid metabolism and mitochondria function were measured during the transition period ( -3 to $3 \mathrm{wk}$ relative to parturition) and reported to assess potential differences in lipid mobilization between groups during the transition period. All cows were fed a common diet throughout lactation (Table 1). Before calving, cows 
were fed a common far-off diet between -6 and -4 wk relative to parturition and a common close-up diet from -3 wk to parturition (Table 1). Except during the RC period, cows were kept in freestalls with ad libitum access to feed and water at the Experimental Animal Facility for Cattle (Dummerstorf, Germany). Feed intake was measured electronically as feed disappearance from troughs (Insentec BV). Cows were milked twice daily (0430 and $1530 \mathrm{~h}$ ) in the milk parlor except during the RC period. Milk yield, feed intake, and BW were recorded daily and averaged for weekly values, in which a week was considered from Sunday to Saturday. Any missing $(\mathrm{n}=2)$ or incorrectly recorded (e.g., $<5 \mathrm{~kg}$ of DM recorded as daily intake, or only morning or evening milk production recorded; $\mathrm{n}=14$ ) daily feed intakes or milk yields were not included in the weekly averages for analysis. Additionally, the daily feed intakes and milk yields from the day animals were moved to the $\mathrm{RC}$ and the day animals were returned to freestalls were removed from weekly averages. Furthermore, at approximately $200 \mathrm{~d}$ of lactation, cows were moved to tiestalls as part of another study, and, as such, daily feed intake and milk yields for animals on the day the animals were moved to and returned from the tiestalls were not included in the weekly averages. Finally, the daily BW data from $1 \mathrm{H}$ cow was missing due to an issue with her identification transmitter, and, as such, we were not able to calculate weekly BW from wk 8 through 22 for her. Percent milk fat, protein, lactose, and milk urea concentration were determined from weekly milk samples consisting of pooled samples from the evening and subsequent morning milking and were analyzed using infrared spectrophotometry (MilkoScan, Foss GmbH) at the Milk Testing Laboratory (Güstrow, Germany). Milk components were weighted for milk volume at time of sampling and used to calculate ECM. Energy-corrected milk was calculated according to the formula proposed by Sjaunja et al. (1990):

$$
\begin{gathered}
\text { ECM }(\mathrm{kg} / \mathrm{d})=\text { milk yield }(\mathrm{kg} / \mathrm{d}) \\
\times\{[383 \times \text { fat }(\%)+242 \times \text { protein }(\%)+165.4 \\
\times \text { lactose }(\%)+20.7] / 3,140\} .
\end{gathered}
$$

Milk energy content (MEC, kJ) was calculated by multiplying ECM $(\mathrm{kg})$ by $3,140 \mathrm{~kJ} / \mathrm{kg}$. One ECM value was removed during wh 7 due to a faulty milk sample, and 6 ECM values were removed between wh 28 and 30 [wk $28(\mathrm{n}=2), 29(\mathrm{n}=3)$, and $30(\mathrm{n}=1)$ ] due to bias in milk yield recording arising from interference from another experiment. A TMR sample was collected weekly for DM analysis and used to calculate DMI. The $\mathrm{ME}$ content of the diet was calculated based on the CP, crude fiber $(\mathrm{CFi})$ and crude fat $(\mathrm{CFa})$ contents according to the recommendations of the German Society of Nutrition Physiology (2003) as suggested by Boguhn et al. (2003):

$$
\begin{gathered}
\mathrm{ME}(\mathrm{MJ} / \mathrm{kg} \text { of } \mathrm{DM})=6.0756+0.19123 \mathrm{CFa} \\
+0.02459 \mathrm{CP}-0.000038 \mathrm{CFi}^{2}-0.002139 \mathrm{CFa}^{2} \\
-0.000060 \mathrm{CP}^{2}
\end{gathered}
$$

and used to calculate the metabolizable energy intake (MEI, MJ) of each cow. Back fat thickness (BFT) and BCS were measured in cows at least twice during the antepartum (AP) period (-6 wk to parturition), at least once in the immediate postpartum $(\mathbf{P P})$ period (parturition to $3 \mathrm{wk}$ ), and at wk 4 ( $\mathrm{n}=9$ for $\mathrm{BFT})$, 6, 8, $10(\mathrm{n}=9)$, and 12 PP. Back fat thickness $(\mathrm{cm})$ was measured according to Schröder and Staufenbiel (2006) using a Titan Ultrasound System (Sonosite Inc.) with a linear probe (L52/10-5 MHz Transducer, Sonosite Inc.), and BCS was assessed based on a 5-point scale. Measurements of BFT and BCS recorded during the AP and PP periods were averaged for each period, and the average was used for future statistical analysis. Changes in BFT and BCS were calculated by taking the difference between 2 sequential time points [e.g., wk 6 - wk 4 (n $=9$ for BFT), wk 8 - wk 6 , etc.]. Additionally, $\triangle \mathrm{BCS}$ and $\triangle \mathrm{BFT}$ were also calculated for change between the AP and PP periods as well as the change between the PP period and wk 4 ( $\mathrm{n}=9$ for $\triangle \mathrm{BFT})$.

Before parturition, cows were halter trained and adapted to the $\mathrm{RC}$ to minimize disturbances to regular eating, drinking, and ruminating behavior. Feed intake depression during the $\mathrm{RC}$ period was expected to occur despite the adaptation, due to the nature of cows being housed in individual RC (e.g., social eating, movement in freestalls, ambient temperature). In previous studies involving RC, the typical drop in feed intake is approximately 1 to $2 \mathrm{~kg}$ DMI (Alemu et al., 2017; Rischewski et al., 2017). To estimate the drop in intake during the RC period, the expected DMI if cows were in freestalls was estimated by averaging DMI values \pm 1 wk relative to the $\mathrm{RC}$ period for each cow and multiplying this value by $23 \mathrm{~h} / 24 \mathrm{~h}$ (estimated DMI/23 h). The difference (i.e., drop in intake) was then calculated for each cow individually by subtracting their measured DMI during the ad libitum feeding period (AD-LIB) in the RC (23 h) from their respective estimated DMI $(23 \mathrm{~h})$. The $\mathrm{RC}$ period consisted of $66 \mathrm{~h}, 18 \mathrm{~h}$ for adaptation and gas equilibrium and $48 \mathrm{~h}$ for measurements, during wk $5.70 \pm 0.82$ (mean \pm SD) PP. During the 18 -h adaptation and the first 24-h measuring period in RC, cows 
Table 1. Ingredients and nutrient composition of diets

\begin{tabular}{|c|c|c|c|}
\hline \multirow[b]{2}{*}{ Diet composition } & \multicolumn{3}{|c|}{ Diet concentration (mean $\pm \mathrm{SD}$ ) } \\
\hline & Far-off & Close-up & Lactation \\
\hline \multicolumn{4}{|l|}{ Ingredient, $\mathrm{g} / \mathrm{kg}$ of $\mathrm{DM}$} \\
\hline Corn silage & $188 \pm 55.4$ & $491 \pm 37.9$ & $401 \pm 31.3$ \\
\hline Concentrate $^{1}$ & - & $111 \pm 12.5$ & $207 \pm 15.0$ \\
\hline Grass or rye silage & $495 \pm 44.2$ & $176 \pm 48.6$ & $213 \pm 29.6$ \\
\hline Corn meal & - & - & $64.7 \pm 3.96$ \\
\hline Rapeseed meal, extracted & - & $31.3 \pm 2.79$ & $47.4 \pm 2.61$ \\
\hline Barley straw & $182 \pm 63.2$ & $37.3 \pm 16.2$ & $19.5 \pm 18.6$ \\
\hline Hay & $127 \pm 56.0$ & $87.3 \pm 17.0$ & - \\
\hline Soybean meal, extracted & - & $50.1 \pm 4.47$ & $18.3 \pm 1.11$ \\
\hline Wheat seeds & - & - & $16.9 \pm 2.39$ \\
\hline Kulmin MFV Plus ${ }^{2}$ & $8.09 \pm 0.46$ & - & - \\
\hline Panto-Mineral R8609 ${ }^{3}$ & - & $14.7 \pm 1.22$ & - \\
\hline Mineral feed $3^{4}$ & - & - & $6.99 \pm 0.39$ \\
\hline Limestone $^{5}$ & - & - & $3.98 \pm 0.21$ \\
\hline Soybean oil & - & - & $1.08 \pm 0.20$ \\
\hline \multicolumn{4}{|c|}{ Nutrient composition, $\mathrm{g} / \mathrm{kg}$ of $\mathrm{DM}$} \\
\hline DM & $429 \pm 37.1$ & $447 \pm 24.2$ & $470 \pm 27.6$ \\
\hline Starch & $53.6 \pm 18.9$ & $171 \pm 10.3$ & $226 \pm 17.9$ \\
\hline Crude fiber & $270 \pm 7.56$ & $205 \pm 9.27$ & $163 \pm 8.70$ \\
\hline $\mathrm{CP}$ & $123 \pm 8.28$ & $148 \pm 5.32$ & $163 \pm 3.82$ \\
\hline Crude ash & $92.4 \pm 8.81$ & $77.1 \pm 3.24$ & $74.2 \pm 2.41$ \\
\hline Crude fat & $25.1 \pm 1.77$ & $25.7 \pm 1.25$ & $30.8 \pm 1.28$ \\
\hline \multicolumn{4}{|l|}{ Energy content, MJ/kg of DM } \\
\hline $\mathrm{ME}$ & $9.37 \pm 0.26$ & $10.7 \pm 0.10$ & $11.4 \pm 0.17$ \\
\hline $\mathrm{NE}_{\mathrm{L}}$ & $5.53 \pm 0.18$ & $6.47 \pm 0.08$ & $7.00 \pm 0.13$ \\
\hline
\end{tabular}

${ }^{1}$ Mix of MF2000 (Vollkraft Mischfutterwerke GmbH: 33\% extracted soy meal, 20\% corn, 17\% wheat gluten, $13 \%$ wheat, $8 \%$ extracted rapeseed meal, $5 \%$ sugar beet pulp, $2 \%$ sodium hydrogen carbonate, $1.3 \%$ calcium carbonate, and $0.2 \%$ sodium chloride) and beet pulp-concentrate mix (Panto Mineral R 8609, HL Hamburger Leistungsfutter GmbH: $20 \% \mathrm{Ca}, 6 \% \mathrm{P}, 8 \% \mathrm{Na}, 6 \% \mathrm{Mg}, 0.03 \% \mathrm{~N}, 13.74 \% \mathrm{P}_{2} \mathrm{O}_{5}$, vitamins, trace elements).

${ }^{2}$ Kulmin MFV Plus (Bergophor $\mathrm{GmbH}$ ): $1.5 \%$ calcium, $7.5 \%$ phosphorous, $8.5 \%$ magnesium, $6.5 \%$ sodium, $2.5 \%$ hydrochloric acid insoluble ash, 1,000,000 IU $/ \mathrm{kg}$ vitamin $\mathrm{A}, 200,000 \mathrm{IU} / \mathrm{kg}$ vitamin $\mathrm{D}_{3}, 10 \mathrm{~g} / \mathrm{kg}$ vitamin $\mathrm{E}, 180 \mathrm{mg} / \mathrm{kg}$ vitamin $\mathrm{B}_{1}, 90 \mathrm{mg} / \mathrm{kg}$ vitamin $\mathrm{B}_{2}, 90 \mathrm{mg} / \mathrm{kg}$ vitamin $\mathrm{B}_{6}, 200 \mathrm{mg}$ calcium-D-pantothenate, 2.5 $\mathrm{g} / \mathrm{kg}$ niacin amide, $675 \mathrm{mg} / \mathrm{kg}$ vitamin $\mathrm{B}_{12}, 12 \mathrm{mg} / \mathrm{kg}$ folic acid, $100 \mathrm{~g}$ biotin, $1 \mathrm{~g} / \mathrm{kg}$ copper-(II)-sulfate, 500 $\mathrm{mg} / \mathrm{kg}$ copper chelate of glycine hydrate, $4.5 \mathrm{~g} / \mathrm{kg}$ zinc oxide, $2.5 \mathrm{mg} / \mathrm{kg}$ zinc chelate of glycine hydrate, 3.5 mg manganese oxide, $1.5 \mathrm{~g}$ manganese chelate of glycine hydrate, $20 \mathrm{mg} / \mathrm{kg}$ cobalt acetate $\times 4 \mathrm{H}_{2} \mathrm{O}, 75 \mathrm{mg} / \mathrm{kg}$ calcium iodate, $30 \mathrm{mg} / \mathrm{kg}$ sodium selenite, $15 \mathrm{mg}$ organic selenium (Saccharomyces cerevisiae).

${ }^{3}$ Panto-Mineral R8609: 20\% calcium, 6\% phosphorous, 8\% sodium, $6 \%$ magnesium, $0.03 \%$ nitrogen, $13.7 \%$ phosphorous oxide; 900,000 IU $/ \mathrm{kg}$ vitamin $\mathrm{A}, 200,000 \mathrm{IU} / \mathrm{kg}$ vitamin $\mathrm{D}_{3}, 4.5 \mathrm{~g} / \mathrm{kg}$ vitamin $\mathrm{E}, 1 \mathrm{~g} / \mathrm{kg}$ copper(II)-sulfate $\times 5 \mathrm{H}_{2} \mathrm{O}, 500 \mathrm{mg} / \mathrm{kg}$ copper chelate of glycine hydrate, $5.3 \mathrm{~g} / \mathrm{kg}$ zinc oxide, $2.7 \mathrm{mg} / \mathrm{kg}$ zinc chelate of glycine hydrate, $3.2 \mathrm{mg}$ manganese oxide, $1.7 \mathrm{~g}$ manganese chelate of glycine hydrate, $60 \mathrm{mg} / \mathrm{kg}$ calcium iodate, $50 \mathrm{mg} / \mathrm{kg}$ sodium selenite.

${ }^{4}$ Fugema GmbH and Co. KG: $47 \%$ dry beet pulp, $25 \%$ extracted soy meal, $24 \%$ rye, $1.4 \%$ urea, $<1 \% \mathrm{NaCl}$, $<1 \% \mathrm{CaNaPO}_{4},<1 \%$ vitamin $\mathrm{E}$, trace elements.

${ }^{5}$ Bergophor $\mathrm{CaCO}_{3}$ V001 (Hohburg Mineralfutter $\mathrm{GmbH}$ ): 37\% Ca.

received $\mathrm{AD}$-LIB feed and then had feed withdrawn for the last $24 \mathrm{~h}$ (RES). Cows were fed at 0700 and $1630 \mathrm{~h}$ during the AD-LIB period. Feed refusals were removed at $0700 \mathrm{~h}$ on $\mathrm{d} 2$, which began the RES period.

During the transition period, 1 cow suffered from mastitis (wk 2 PP; L group); 2 cows suffered from a retained placenta (wk $1 \mathrm{PP} ; \mathrm{H}$ and $\mathrm{L}$ groups), of which the L cow was also suffering from interdigital phlegmon; 1 cow suffered from endometritis (wk 2 PP; L group); and, finally, 1 cow suffered from peritonitis (wk 3 PP; L group). While in the RC, 1 cow had digital dermatitis, and 1 cow was being treated for endometritis (both in L group). No other animals exhibited signs of illness during the transition period or the weeks leading up to their respective entry into the RC. All animals were treated and cared for by veterinarians and the farm crew as appropriate.

\section{Data Collection and Analysis}

Plasma. Blood was sampled once weekly at approximately $0700 \mathrm{~h}$ from -3 to 12 wk PP. Additionally, blood was sampled at 0700 before entry to the RC and at the end of the AD-LIB and RES feeding periods in the RC. Blood samples were collected from the jugular vein in Vacuette blood collection tubes (Greiner Bio-One Inter- 
national) containing $\mathrm{NaF}$ or $\mathrm{K}_{2}$ EDTA. Samples were centrifuged at $1,570 \times g$ for $20 \mathrm{~min}$ at $4^{\circ} \mathrm{C}$ to obtain plasma and stored at $-20^{\circ} \mathrm{C}$ until analysis. Plasma was analyzed photometrically (Abx Pentra 400, Horiba) for concentrations of glucose (A11A01667, Axon Lab AG), triglyceride (A11A01640, Axon Lab), nonesterified fatty acids (NEFA; Wako Chemicals), BHB (RB 1007, Labor+Technik Lehmann), lactate (A11A01721, Axon Lab), urea (LT-UR 0010, Labor+Technik Lehmann), bilirubin (A11A01639, Axon Lab), creatine kinase (n = 9 for wk 10; $\mathrm{n}=9$ for RES period; A11A01632, Axon Lab), aspartate aminotransferase (AST; A11A01629, Axon Lab), cholesterol (553-300, MTI Diagnostics), and glutamate dehydrogenase (LT-GD 0010, Labor+Technik Lehmann). Insulin was measured via RIA (no. 1257; DRG International Inc.) with an intra-assay variation of $3.7 \%$ and interassay variation of 5.0 to $6.0 \%$. Insulin was converted from $1 \mu \mathrm{U} / \mathrm{mL}$ to $\mathrm{pmol} / \mathrm{L}$ by multiplying that value by 6.00 , as recommended by Knopp et al. (2019). Glucagon concentrations were analyzed via RIA (GL-32K; Linco Research) with an intra-assay variation of $3.4 \%$ and an interassay variation of 16.3 to $28.6 \%$. The Revised Quantitative Insulin Sensitivity Check Index (RQUICKI, RQUIKI with BHB correction) and Homeostasis Model Assessment were calculated as described by Guyot et al. (2017). Plasma Trp was measured by HPLC and fluorescence detector as described by Kuhla et al. (2010), and plasma kynurenine (Kyn) was measured by HPLC connected with a variable wavelength detector as modified from Stracke et al. (2017). Briefly, the HPLC system for measurement of Kyn was equipped with a $250 \times 4$-mm HyperClone 5 uMODS (C18) $120-\AA ̊$ column protected by a $4 \times 3$-mm C18 pre-column (Phenomenex) set at a temperature of $25^{\circ} \mathrm{C}$. Samples were injected at $20 \mu \mathrm{L}$ with a mobile phase of $\mathrm{KH}_{2} \mathrm{PO}_{4}(0.02 M, \mathrm{pH} 6.5)$ and flow rate of $1 \mathrm{~mL} / \mathrm{min}$. Samples were analyzed at a wavelength of $363 \mathrm{~nm}$ with an elution time of approximately 11 to 12 min. Before analysis for Kyn, protein precipitation was performed on $0.12-\mathrm{mL}$ plasma samples using $0.08 \mathrm{~mL}$ of $1.5 \mathrm{M} \mathrm{HClO}_{4}$ and $0.04 \mathrm{~mL}$ of $2 \mathrm{M} \mathrm{K}_{2} \mathrm{CO}_{3}$.

Respiration Chamber. Individual feed intake (kg), $\mathrm{CO}_{2}(\mathrm{~L}), \mathrm{O}_{2}(\mathrm{~L})$, and $\mathrm{CH}_{4}(\mathrm{~L})$ were measured every 6 min for $24 \mathrm{~h}$ as described by Derno et al. (2019); however, data were considered only for $23 \mathrm{~h}$ (0700 to $0600 \mathrm{~h}$ ), to eliminate interferences from feed removal and blood sampling in the chamber. Gas recovery from RC was $99.9 \% \pm 0.96 \%$ (mean $\pm \mathrm{SD}$ ), as determined by $\mathrm{CO}_{2}$ span gas injections. Concentrations of $\mathrm{CO}_{2}$ and $\mathrm{CH}_{4}$ were measured by infrared absorption (SIDOR, Sick $\mathrm{AG}$ ), and $\mathrm{O}_{2}$ concentrations were measured paramagnetically (SIDOR, Sick AG) every $6 \mathrm{~min}$. The airflow through the chamber was approximately $30 \mathrm{~m}^{3} / \mathrm{h}$ and was measured by a differential pressure-type $\mathrm{V}$ cone flow meter (McCrometer Inc.). Cows were milked twice daily $(0630$ and $1630 \mathrm{~h}$ ) during the RC period. Cows were weighed before entering and after exiting the RC. The initial BW was considered the AD-LIB BW, and the secondary BW was considered the RES BW. These $\mathrm{BW}$ were used to determine the metabolic BW $(\mathbf{m B W}$, calculated as $\mathrm{BW}^{0.75}$ ) for each individual cow during the AD-LIB and RES periods.

Heat production was calculated according to Brouwer (1965) as follows:

$$
\begin{aligned}
\mathrm{HP}(\mathrm{kJ})= & 16.18 \times \mathrm{O}_{2}+5.02 \times \mathrm{CO}_{2}-2.17 \\
& \times \mathrm{CH}_{4}-5.99 \times \mathrm{N}_{\mathrm{u}},
\end{aligned}
$$

where $\mathbf{N}_{\mathbf{u}}$ is $\mathrm{N}$ excreted in urine in grams, and gases are expressed in liters. Because we did not collect urine in this experiment, $N_{u}$ was estimated to be $100 \mathrm{~g}$ of $\mathrm{N}_{\mathrm{u}} / \mathrm{d}$ for all cows, thereby accepting an error of about $0.4 \%$ in HP (Derno et al., 2019).

Furthermore, because measured $\mathrm{CO}_{2}$ consists of $\mathrm{CO}_{2}$ from metabolic and fermentative processes, we estimated fermentative $\mathrm{CO}_{2}$ according to Chwalibog et al. (1996):

$$
\text { Fermentative } \mathrm{CO}_{2}=1.7 \times \mathrm{CH}_{4} \text {, }
$$

where the gases are expressed in liters. We then subtracted that estimate from total $\mathrm{CO}_{2}$ to estimate metabolic $\mathrm{CO}_{2}\left(\mathbf{m C O}_{2}\right.$; Derno et al., 2013). Metabolic $\mathrm{CO}_{2}$, in turn, was used to calculate the metabolic respiratory quotient (RQ), net FOX, and net COX. Net FOX and COX were calculated according to Frayn (1983):

$$
\operatorname{FOX}(\mathrm{g})=1.67 \times \mathrm{O}_{2}-1.67 \times \mathrm{mCO}_{2}-1.92 \times \mathrm{N}_{\mathrm{u}}
$$

and

$$
\mathrm{COX}(\mathrm{g})=4.55 \times \mathrm{mCO}_{2}-3.21 \times \mathrm{O}_{2}-2.87 \times \mathrm{N}_{\mathrm{u}}
$$

As with HP, $\mathrm{N}_{\mathrm{u}}$ was estimated to be $100 \mathrm{~g}$ of $\mathrm{N}_{\mathrm{u}} / \mathrm{d}$ for all cows, and gases are expressed in liters. The percent of FOX/HP and COX/HP was calculated by multiplying FOX and COX by $37 \mathrm{~kJ} / \mathrm{g}$ and $17 \mathrm{~kJ} / \mathrm{g}$, respectively, dividing by HP (kJ), and multiplying by 100 .

Daily sums of total DMI, MEI, $\mathrm{CO}_{2}, \mathrm{mCO}_{2}, \mathrm{O}_{2}, \mathrm{CH}_{4}$, FOX, and COX were determined by summing all measured time points for each variable over a 23 -h period for each feeding period. Average RQ was determined by averaging the RQ from all measured time points over a 23-h period for each feeding period. Energy balance was calculated for the AD-LIB and RES period as follows: 
Energy balance $(\mathrm{MJ} / 23 \mathrm{~h})=\mathrm{MEI}(\mathrm{MJ} / 23 \mathrm{~h})$

$$
\begin{gathered}
-\mathrm{HP}(\mathrm{MJ} / 23 \mathrm{~h})-[\text { estimated MEC }(\mathrm{MJ} / 24 \mathrm{~h}) \\
\times 23 \mathrm{~h} / 24 \mathrm{~h}] .
\end{gathered}
$$

Milk yield and milk constitutes measured 1 wk before and after the RC period for each cow were used to estimate ECM $(\mathrm{kg})$ and MEC (kJ) during the RC period as previously described. Both BCS and BFT were estimated for the $\mathrm{RC}$ period by averaging values $\pm 1 \mathrm{wk}$ relative to the $\mathrm{RC}$ period for each cow.

Liver. Cows were biopsied at $-4(\mathrm{n}=9), 2(\mathrm{n}=8)$, and $12(\mathrm{n}=10)$ wk relative to parturition. Before biopsy, cows were moved to a stanchion in the Experimental Animal Facility for Cattle. Additionally, sections of the liver were visualized by ultrasound to establish the position of the liver and avoid injuries to the intestine or larger liver vessels. The biopsy was prepared by cleaning, shaving, and disinfecting an area of about $30 \times 30$ $\mathrm{cm}$ on the right flank of the animal. A local anesthetic (10 $\mathrm{mL}$ of procain hydrochloride) was administered to the last intercostal space 1 handsbreadth below the processus transversi. A small incision through the cutis and the superficial muscle was made using a scalpel, and a minimum of $2 \mathrm{~g}$ of liver tissue was biopsied by pushing the biopsy needle (outer diameter of $6 \mathrm{~mm}$ with a sharp trocar inside) first into the abdominal cavity and then in a frontal direction. Tissue samples were separated into 3 aliquots, immediately frozen in liquid nitrogen, and stored at $-80^{\circ} \mathrm{C}$ until analysis.

Frozen liver tissue was ground with liquid nitrogen using a mortar and pestle, and DNA was extracted from approximately $30 \mathrm{mg}$ of frozen, ground tissue using an innuPREP DNA mini kit according to the manufacturer's protocol (Analytik Jena). After the lysis step, DNA samples $(\sim 400 \mu \mathrm{L})$ were treated with $2 \mu \mathrm{L}$ of RNase (10 mg/mL; Carl Roth GmbH and Co. KG) at room temperature for 5 min. Purity and concentration of DNA were assessed by absorbance readings at $260 \mathrm{~nm}$ and $280 \mathrm{~nm}$ using a NanoPhotometer (Implen $\mathrm{GmbH}$ ), and the integrity of the DNA was assessed by gel electrophoresis (225 ng of DNA per well). Two sets of primers, $12 \mathrm{~S}$ rRNA and cyclophilin A, were used to amplify mitochondrial and nuclear DNA PCR products, respectively: $12 \mathrm{~S}$ rRNA-forward CGCGGTCATACGATTAACCC, 12S rRNA-reverse AACCCTATTTGGTATGGTGCTT, cyclophilin A-forward GGTCCTGGCATCTTGTCCAT, and cyclophilin A-reverse TGGCAGTGCAAATGAAAAACTG (Laubenthal et al., 2016; Du et al., 2018). Amplification of the primer products was performed in triplicate using real-time qPCR on a Light Cycler 2.0 (Roche). Each PCR reaction contained $2 \mu \mathrm{L}$ of diluted DNA $(7.5 \mathrm{ng} / \mu \mathrm{L}), 6$ $\mu \mathrm{L}$ of Light Cycler FAST DNA Master PLUS SYBR
Green I Reaction Mix (Roche), $3 \mu \mathrm{L}$ of nuclease-free water, and $1 \mu \mathrm{L}$ of the respective primer mix $(10 \mathrm{pmol} /$ $\mu \mathrm{L}$ ) for a final volume of $12 \mu \mathrm{L}$. A pooled DNA sample was used as an inter-run calibrator. The PCR efficiency of amplification (1.82-1.94) and cycle threshold (Ct) values were calculated using LinRegPCR software, version 2014.4 (Academic Medical Centre). Based on the Ct values, relative mitochondrial DNA (mtDNA) content was calculated according to Gonzalez-Hunt et al. (2016) as follows:

$$
\begin{aligned}
& \text { Relative mitochondrial DNA content }= \\
& \qquad 2 \times 2^{(\text {nuclearDNA Ct }- \text { mtDNA Ct })} .
\end{aligned}
$$

\section{Statistical Analysis}

Data were analyzed with mixed models (PROC MIXED) using SAS software (version 9.4, 2013; SAS Institute Inc.). Lactation data collected weekly from wk 4 through 30; plasma data, BCS, BFT, $\triangle \mathrm{BCS}$, and $\triangle \mathrm{BFT}$ from wk 4 to $12 \mathrm{PP}$; plasma data, BCS, and $\mathrm{BFT}$ collected during the transition period; and relative mtDNA content were analyzed with the fixed effects of feed efficiency group, week relative to parturition, and their interaction, and the random effect of cow. Repeated measures were used in the above models, and week was used in the repeated statement, with the subject defined as cow. The covariance structure was first-order autoregressive for all data except BCS, $\triangle \mathrm{BCS}$, BFT, $\triangle \mathrm{BFT}$, and AST, which used a Toeplitz covariance structure, and relative mtDNA content, which used a spatial power covariance structure. Covariance structures were chosen based on lowest Bayesian information criterion score. Denominator degrees of freedom were estimated by using the Kenward-Roger option in the MODEL statement, and paired differences were determined using the SLICE option in PROC MIXED.

Data collected over the RC period were analyzed with the fixed effects of feed efficiency group, feeding period, and their interaction, and the random effect of cow. Denominator degrees of freedom were estimated by using the Kenward-Roger option in the MODEL statement, and paired differences were determined using the diff option in PROC MIXED.

Two-tailed $t$-tests assuming unequal variances were performed on JMP Pro software (version 14.2, 2018; SAS Institute Inc.) to detect differences between $\mathrm{H}$ and $\mathrm{L}$ for $\mathrm{CH}_{4} / \mathrm{DMI}(\mathrm{L} / \mathrm{kg}), \mathrm{COX} / \mathrm{DMI}(\mathrm{g} / \mathrm{kg})$, FOX/DMI $(\mathrm{g} / \mathrm{kg})$, and HP/DMI $(\mathrm{MJ} / \mathrm{kg})$ during the AD-LIB period; estimated $\mathrm{ECM}, \mathrm{ECM} / \mathrm{mBW}, \mathrm{BFT}$, and $\mathrm{BCS}$ during the RC period; the difference between the estimated DMI/23 $\mathrm{h}$ in the barn and the actual DMI/23 $\mathrm{h}$ measured during the AD-LIB period in the RC; and 
$\triangle \mathrm{BCS}$ and $\triangle \mathrm{BFT}$ during the transition period (AP $\mathrm{PP}$ ) and between the PP period and wk $4 \mathrm{PP}$.

Main effects and interactions were declared significant at $P \leq 0.05$, and tendencies for main effects and interactions were declared at $0.05<P \leq 0.10$. Transformations were applied to response variables that violated the assumptions of normality, homogeneity of residuals, or both, based on visual inspection of QQ-plots and graphing the residual versus the predicted value. Data transformed are noted in the tables and figures along with the transformation used for statistical analysis. The means of the observed data are presented in the texts, tables, and figures for interpretation purposes.

\section{RESULTS}

\section{Weeks 4 Through 30 of Lactation}

Neither BW, DMI, MEI, MEI/mBW, milk yield, milk components, nor ECM differed between groups $(P$ $>0.10$; Table 2$)$, but $\mathrm{H}$ had greater $\mathrm{ECM} / \mathrm{mBW}(P=$ $0.01)$ and tended to have higher milk yield $/ \mathrm{mBW}$ and $\mathrm{DMI} / \mathrm{mBW}$ than $\mathrm{L}(P \leq 0.10)$. The ratios of ECM/ DMI and MEC/MEI were greater for $\mathrm{H}$ compared with $\mathrm{L}(P \leq 0.02)$, as anticipated. All traits significantly differed by week $(P<0.01)$ except for milk protein yield and milk urea $(P>0.10)$. No significant group by week interactions were detected for any production traits.

The BCS was lower in $\mathrm{H}$ compared with $\mathrm{L}(P=$ 0.04; Table 3 ), but $\triangle \mathrm{BCS}$ did not differ between groups
$(P=0.62)$. Additionally, neither BFT nor $\triangle$ BFT differed between groups $(P \geq 0.35)$. None of the plasma metabolites measured significantly differed between groups ( $P>0.10$; Table 3$)$; however, plasma glucose, BHB, and AST concentrations had significant group by week interactions (Figure 1; $P \leq 0.05$ ). Plasma AST concentration did not differ between groups at any weekly time points, but plasma glucose concentration tended to be higher for $\mathrm{L}$ compared with $\mathrm{H}$ at wk 5 (pairwise test, $P=0.06$ ), and $\mathrm{H}$ had a higher plasma BHB concentration than $\mathrm{L}$ at wk 4 (pairwise test, $P<$ $0.01)$.

\section{Respiration Chamber}

In wk 5.70 PP, gas exchange of the cows was measured during AD-LIB and RES, and all nonplasma parameters were found significantly different between feeding periods $(P \leq 0.03$; Table 4$)$. The $\mathrm{H}$ group had lower HP compared with L (115 vs. $133 \mathrm{MJ} ; P=0.05$ ), and this difference persisted when HP was adjusted for $\mathrm{mBW}\left[967\right.$ vs. $1,032 \mathrm{~kJ} /\left(\mathrm{kg}\right.$ of $\left.\mathrm{BW}^{0.75} \times 23 \mathrm{~h}\right) ; P=$ 0.04]. Additionally, $\mathrm{H}$ had lower FOX compared with $\mathrm{L}(1,367$ vs. $1,915 \mathrm{~g} / 23 \mathrm{~h} ; P=0.04)$, and $\mathrm{H}$ tended to have lower $\mathrm{FOX} / \mathrm{mBW}$ compared with L [13.6 vs. 16.7 $\mathrm{g} /\left(\mathrm{kg}\right.$ of $\left.\left.\mathrm{BW}^{0.75} \times 23 \mathrm{~h}\right) ; P=0.06\right]$. Furthermore, FOX, $\mathrm{FOX} / \mathrm{mBW}$, COX/FOX, COX/HP, FOX/HP, and average RQ differed or tended to differ between groups across feeding periods (interaction, $P<0.10$ ).

Table 2. Production characteristics from wk 4 to 30 postpartum of second-lactation dairy cows grouped by either high or low feed efficiency $(\mathrm{ECM} / \mathrm{DMI})^{1}$

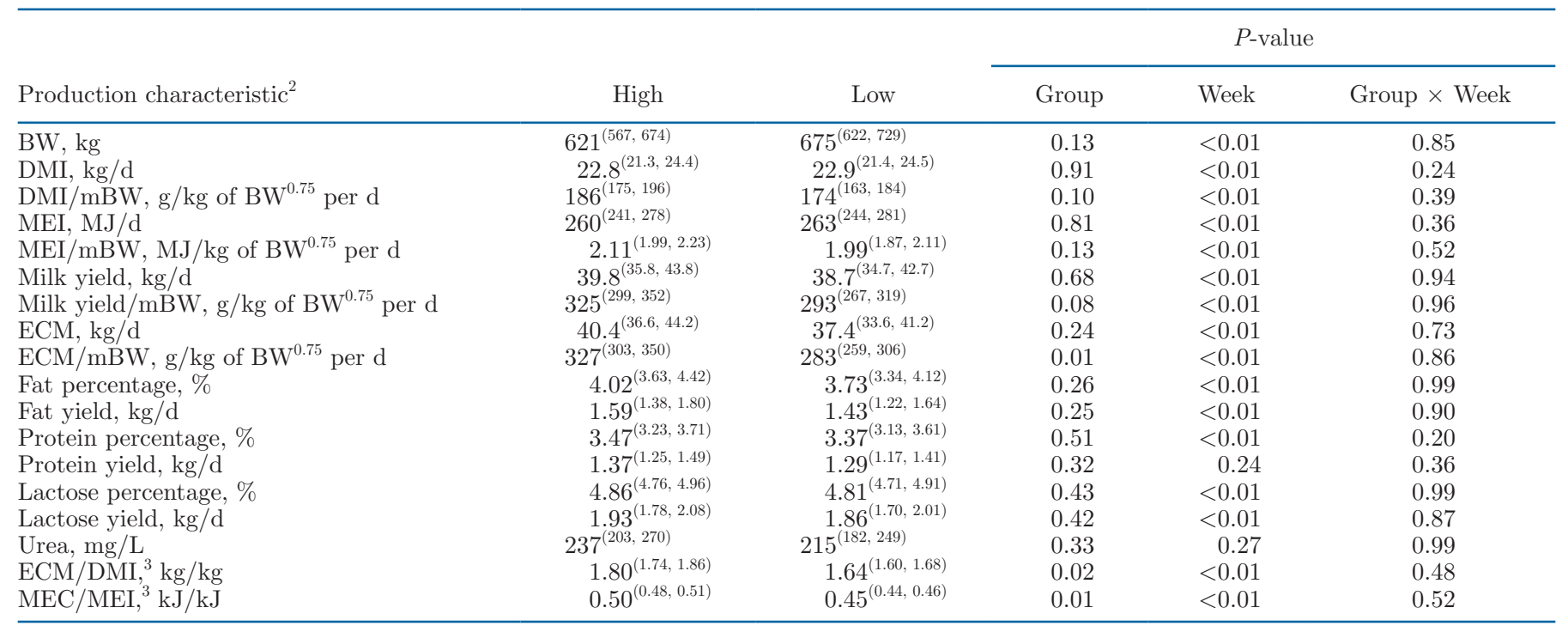

${ }^{1}$ Values presented as $\operatorname{LSM}^{(95 \% \mathrm{CI})}$ unless otherwise noted.

${ }^{2} \mathrm{MEI}=$ metabolizable energy intake; $\mathrm{MEC}=$ milk energy content; $\mathrm{mBW}=$ metabolic $\mathrm{BW}$.

${ }^{3}$ Data transformed using the reciprocal for statistical analysis, and mean of observed data ${ }^{(95 \% \mathrm{CI})}$ reported for interpretation. 
The $\mathrm{H}$ cows tended to have a higher average RQ and COX/HP compared with $\mathrm{L}$ during AD-LIB (pairwise test, $P=0.07$ ), and $\mathrm{H}$ tended to have a lower FOX/ HP compared with L during AD-LIB (pairwise test, $P$ $=0.06)$. Energy balance did not differ between groups (H: -146 vs. L: $-149 \mathrm{MJ} / 23 \mathrm{~h} ; P=0.87)$. All measured gases differed or tended to differ between groups $(P \leq 0.10)$, and $\mathrm{CO}_{2} / \mathrm{mBW}, \mathrm{mCO}_{2}$, and $\mathrm{mCO}_{2} / \mathrm{mBW}$ differed or tended to differ between groups across feeding periods (interaction, $P \leq 0.08$ ). Additionally, the emission intensity $\left(\mathrm{CH}_{4} / \mathrm{kg}\right.$ of milk yield) was lower in $\mathrm{H}$ than $\mathrm{L}(7.35$ vs. $9.11 \mathrm{~L} / \mathrm{kg}$ of milk yield; $P=0.03$ ).

We detected no significant group or group by feeding period interactions $(P \geq 0.19$; Table 4$)$ for plasma metabolites except for RQUICKI, which tended to have a group by feeding period interaction $(P=0.08)$. However, $\mathrm{H}$ and $\mathrm{L}$ did not differ between groups within feeding periods for RQUICKI (pairwise tests, $P \geq 0.19$ ). Feeding period had or tended to have a significant effect on all measured plasma metabolites $(P \leq 0.06)$ except RQUICKI and RQUICKI with BHB $(P \geq 0.15)$. We observed no differences in BW, DMI, MEI, or milk yield between groups during the RC period (Table 4).

As expected, DMI was numerically decreased during the $\mathrm{RC}$ period compared with the estimated DMI [H: $18.0 \pm 2.54$ (mean $\pm \mathrm{SD}$ ); L: $20.8 \pm 2.02 \mathrm{~kg} / 23 \mathrm{~h}]$ with a decrease of approximately $0.91 \pm 1.40$ and $2.52 \pm 2.23$ $\mathrm{kg} / 23 \mathrm{~h}$ for $\mathrm{H}$ and $\mathrm{L}$, respectively; however, this difference did not significantly differ between groups $(P=$ 0.21). When adjusted for DMI, $\mathrm{CH}_{4} / \mathrm{DMI}$ did not differ between groups $(P=0.16$; Table 5$)$, nor did HP/DMI $(P=0.26)$. Although COX/DMI did not differ between groups $(P=0.13)$, FOX/DMI tended to be lower for $\mathrm{H}$ compared with $\mathrm{L}(P=0.09)$. Neither $\operatorname{BCS}(P=$ $0.14)$ nor BFT $(P=0.89)$ differed between groups. We also detected no difference in estimated ECM between groups $(P=0.37)$, but estimated $\mathrm{ECM} / \mathrm{mBW}$ tended to be greater for $\mathrm{H}$ compared with $\mathrm{L}(P=0.10)$.

\section{Transition Period and Liver Mitochondrial DNA Copy Number}

To examine whether differences in feed efficiency are related to mitochondrial density, we analyzed relative mtDNA copy number per cell in liver tissue. We found greater relative mtDNA content for $\mathrm{H}$ compared with L $\left[\mathrm{LSM}^{(95 \% \mathrm{CI})}\right) ; \mathrm{H}: 479^{(311,648)}$ vs. L: $338^{(161,515)}$ relative mtDNA content; $P=0.04$ ), but no week or week by group interactions $(P=0.67$; Figure 2$)$.

We detected no differences in plasma glucose, insulin, triglyceride, or BHB concentrations between groups in the transition period (Table 6). However, plasma NEFA concentration was greater in $\mathrm{H}$ compared with $\mathrm{L}(P$ $=0.01$ ), and L had a greater concentration of plasma lactate at wk $-1 \mathrm{PP}$ compared with $\mathrm{H}$ (pairwise test, $P=0.04$; Figure 3). Furthermore, Trp concentration, but not the Kyn/Trp ratio, was higher for L compared with $\mathrm{H}$ at 1 wk PP (pairwise test, $P=0.05$; Figure 3 ).

Although a significant group by week interaction was detected for BCS, no differences were detected between

Table 3. Weekly effects of plasma metabolites and biweekly effects of BCS and back fat thickness (BFT) from wk 4 to 12 postpartum in secondlactation dairy cows grouped by either high or low feed efficiency (ECM/DMI) ${ }^{1}$

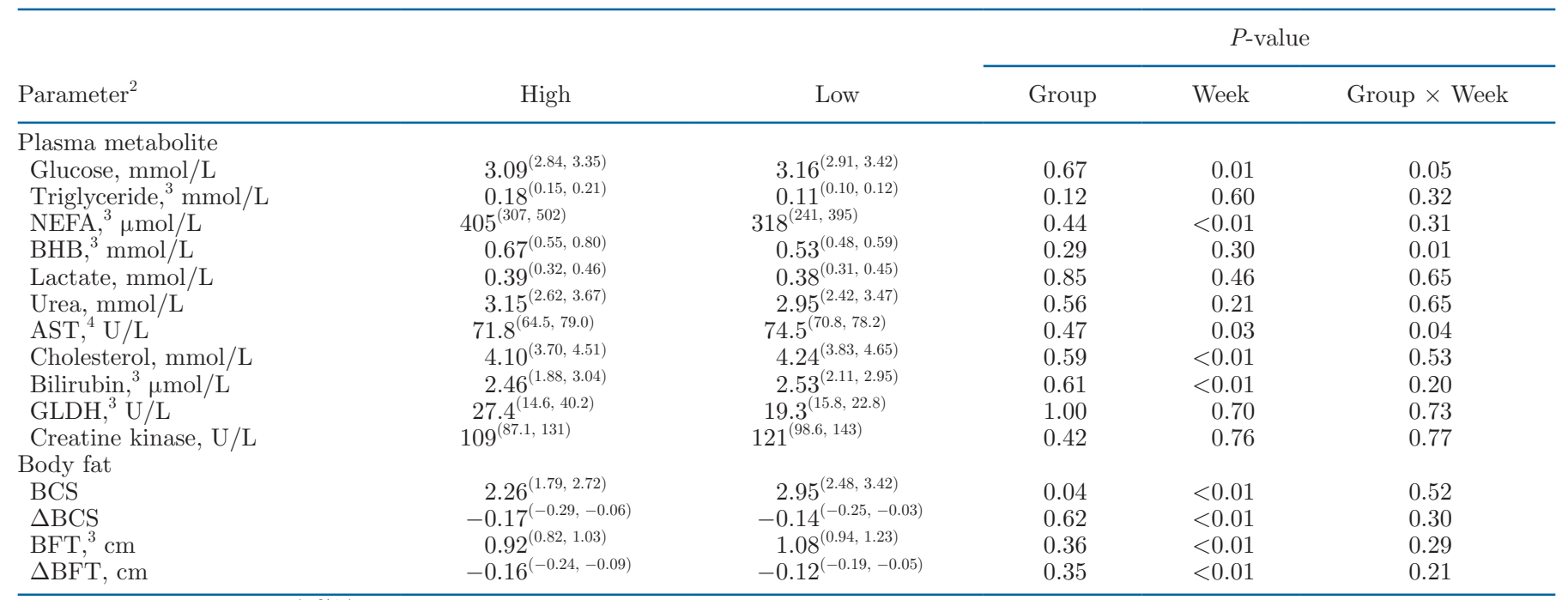

${ }^{1}$ Values presented as $\operatorname{LSM}^{(95 \% \mathrm{CI})}$ unless otherwise noted.

${ }^{2} \mathrm{NEFA}=$ nonesterified fatty acids; AST $=$ aspartate aminotransferase; GLDH = glutamate dehydrogenase.

${ }^{3}$ Data natural log-transformed for statistical analysis, and mean of observed data ${ }^{(95 \% \mathrm{CI})}$ reported for interpretation.

${ }^{4}$ Data transformed using the reciprocal for statistical analysis, and mean of observed data ${ }^{(95 \% \mathrm{CI})}$ reported for interpretation. 
A

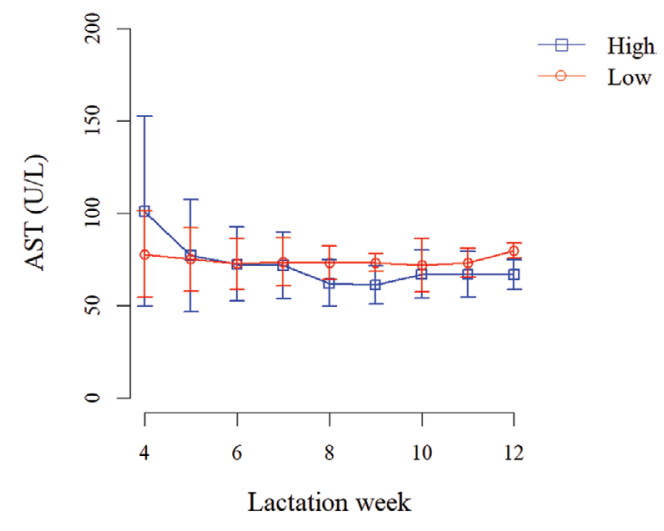

B

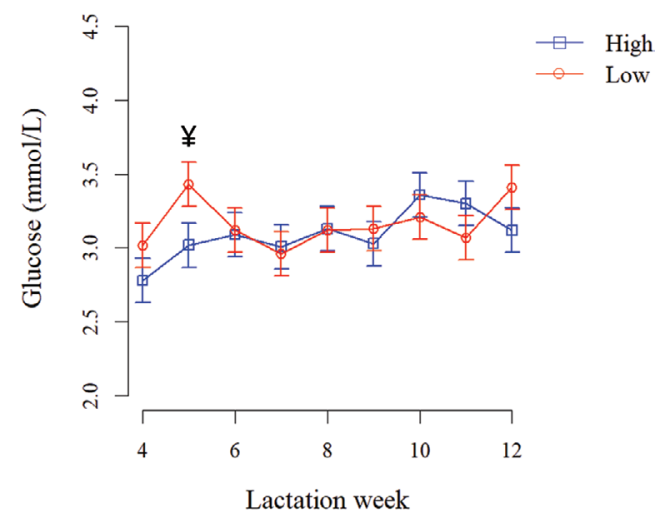

C

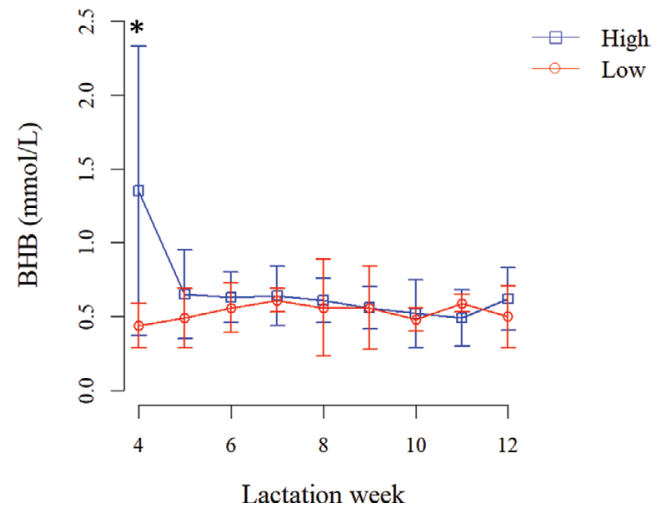

Figure 1. The weekly plasma concentration of (A) aspartate aminotransferase (AST; U/L), (B) glucose $(\mathrm{mmol} / \mathrm{L})$, and $(\mathrm{C}) \mathrm{BHB}$ $(\mathrm{mmol} / \mathrm{L})$ from wk 4 to 12 postpartum in second-lactation dairy cows grouped by either high (blue) or low (red) feed efficiency (ECM/DMI). An asterisk indicates significant differences between groups at a time point $(P \leq 0.05)$; $¥$ indicates tendencies for differences $(0.05<P \leq$ 0.10). $P$-values for AST, glucose, and BHB are given in Table 3. Error bars indicate SEM, unless otherwise noted. The plasma concentration of AST was transformed using the reciprocal for statistical analysis, and the mean of the observed data \pm SD is shown for interpretation. The plasma concentration of BHB was transformed using the natural $\log$ for statistical analysis, and the mean of the observed data $\pm \mathrm{SD}$ is shown for interpretation. groups when sliced by week (Figure 4A). However, the $\triangle \mathrm{BCS}$ between the AP and PP period was greater for $\mathrm{H}$ compared with $\mathrm{L}[\mathrm{H}: 0.32 \pm 0.06$ (mean $\pm \mathrm{SD})$ vs. L: $0.02 \pm 0.22 ; P=0.03]$, but not $\triangle \mathrm{BFT}(\mathrm{H}: 0.13 \pm 0.08$ vs. L: $0.06 \pm 0.22 ; P=0.51)$. We detected no difference in $\triangle \mathrm{BCS}$ (H: $0.72 \pm 0.31$ vs. L: $0.52 \pm 0.22 ; P=0.30$ ) nor $\triangle \mathrm{BFT}$ (H: $0.48 \pm 0.23$ vs. L: $0.26 \pm 0.21 ; P=0.18$ ) between the PP period and 4 wk PP.

\section{DISCUSSION}

Despite the difference in ECM/DMI designed by grouping, we detected only slight differences between $\mathrm{H}$ and $\mathrm{L}$ in production traits from wk 4 to $30 \mathrm{PP}$ and plasma metabolites from wk 4 to $12 \mathrm{PP}$. Although no statistical difference was noted between groups for BW, we observed a numerical difference of approximately $54 \mathrm{~kg}$. Given that most differences and tendencies for differences were noted when production traits were standardized to $\mathrm{mBW}$, we suspect that BW is an important factor influencing our results and that perhaps our sample size may have influenced our ability to detect differences in some traits. Milk yield tended to differ and ECM significantly differed between groups when adjusted for $\mathrm{mBW}$, which likely drives the differences noted in ECM/DMI and MEC/MEI, despite a tendency for $\mathrm{H}$ to have a higher $\mathrm{DMI} / \mathrm{mBW}$ compared with L. Neither milk fat, protein, nor lactose percentage differed between groups; therefore, the tendency for milk yield $/ \mathrm{mBW}$ is likely the principal contributor to the differences in $\mathrm{ECM} / \mathrm{mBW}$ and, by extension, ECM/DMI and MEC/MEI.

In our study, we observed that L cows had higher $\mathrm{HP}$ than $\mathrm{H}$ cows, which mirrors the results of previous studies performed in beef cattle (Basarab et al., 2003; Nkrumah et al., 2006; Cantalapiedra-Hijar et al., 2018). Although Guinguina et al. (2020) did not observe differences in HP in dairy cattle grouped by ECM/DMI, when the same group of cattle were organized by RFI, significant differences in HP were detected, in that high RFI (i.e., less efficient) animals had higher HP than low RFI (i.e., more efficient) animals. Perhaps the differences in HP noted between these 2 groupings is related to DMI, as the low RFI animals consumed less feed than the high RFI animals, but no difference in DMI was noted when those cows were grouped by ECM/ DMI (Guinguina et al., 2020). Indeed, our results also suggest that DMI strongly influences HP, because we noted no difference between groups when HP was corrected for DMI (HP/DMI), and HP was greater in the AD-LIB than in the RES period. However, differences in HP are often speculated to be partially caused by maintenance requirement differences between animals as well (Basarab et al., 2003; Cantalapiedra-Hijar et 
Kennedy et al.: OXIDATION DIFFERENCES IN FEED EFFICIENCY

9296

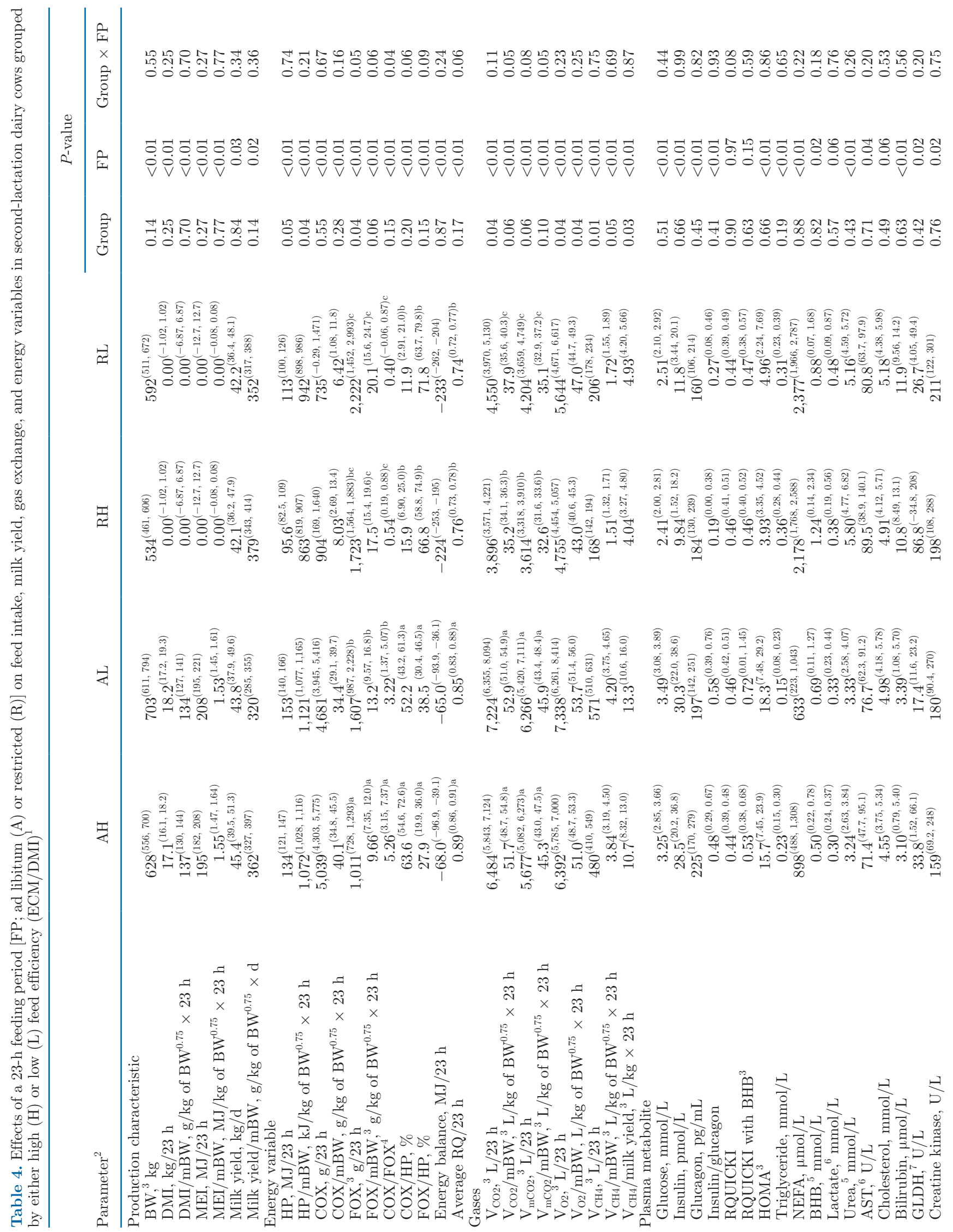




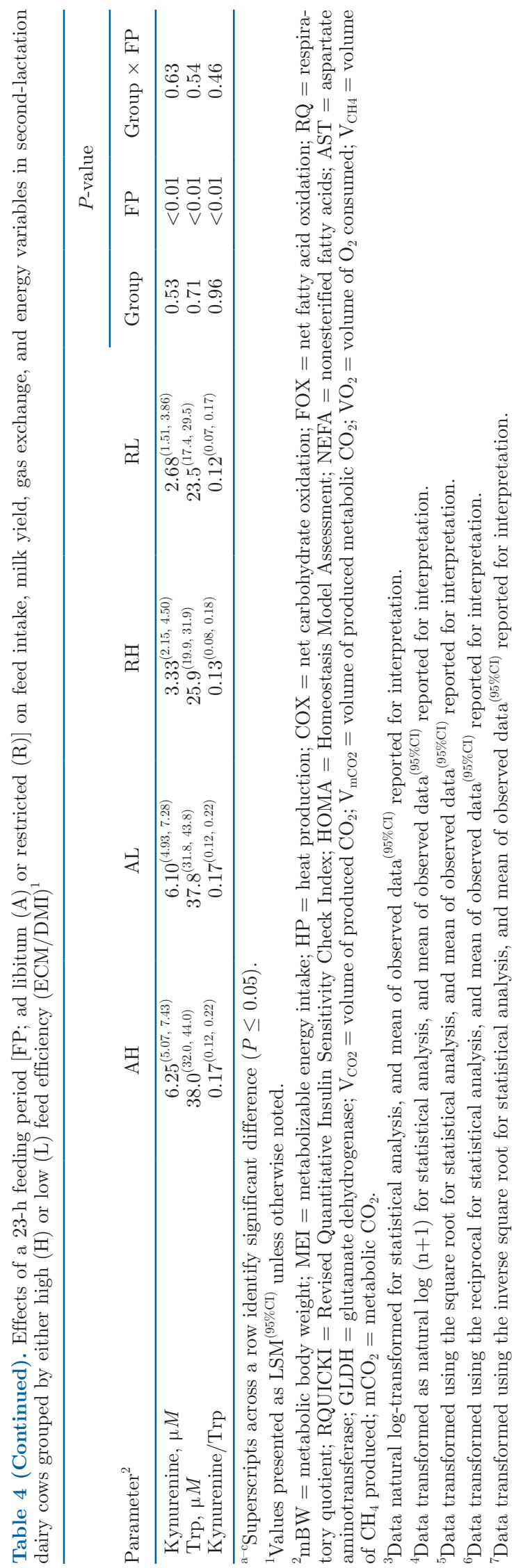

al., 2018). Moreover, body mass, body composition, and surface area are also correlated with HP. In our experiment we observed no significant differences in $\mathrm{BW}$, but we did find a numerical difference that may have influenced differences detected in HP. However, differences in HP persisted when HP was adjusted for $\mathrm{mBW}$, suggesting that BW, although a factor, is not the principal factor responsible for differences in HP in our experiment. Because our animals had no difference in DMI or milk yield during the RC period, with or without a correction for $\mathrm{mBW}$, we speculate that the difference in HP is likely partially associated with the maintenance requirements, as indicated by the higher $\mathrm{O}_{2}$ consumption and $\mathrm{mCO}_{2}$ production of $\mathrm{L}$ cows. Furthermore, although L had a higher BCS than $\mathrm{H}$ during wk 4 to $12 \mathrm{PP}$, the $\triangle \mathrm{BCS}$ during these weeks did not differ, suggesting that the mobilization of body tissue was similar. This is further supported by the lack of detected differences in plasma NEFA concentration during wk 4 to 12 PP. Notably, plasma BHB concentration was higher in $\mathrm{H}$ compared with $\mathrm{L}$ at wk 4, which is likely related to wk 2 and 3 of the transition period, yet, from wk 5 onward and during the RC period, no significant differences in plasma BHB concentration were observed. These results further support that we achieved our intention of measuring fuel oxidation after the initial lipid mobilization phase typically associated with the transition period. As further support that lipid mobilization was similar between groups after wk 4 of lactation, we observed no differences in energy balance between the 2 groups during the RC period, which was likely due to numerically higher milk yield in $\mathrm{H}$ and numerically higher DMI in L during the RC period, thereby leveling energy balance.

However, during the transition period, $\mathrm{H}$ had a higher mobilization of lipids, as supported by a significant increase in plasma NEFA concentration and $\triangle \mathrm{BCS}$ (between the AP and PP period) compared with L. We can only speculate whether $\mathrm{H}$ cows would have had greater FOX and HP if cows had been measured in wk 2 or $3 \mathrm{PP}$, but a higher fat mobilization after parturition does not have to be accompanied by a higher FOX, because different metabotypes of dairy cows exhibit a variable range in their lipolysis sources and fat utilization levels (Weber et al., 2013; Ghaffari et al., 2020). Nevertheless, future research should be conducted to determine whether differences in FOX and HP are present in dairy cows grouped by feed efficiency during the transition period when lipid mobilization is increased.

Notably, we calculated metabolic HP, which excludes the measurement of heat produced from rumen fermentation, as indicated by the subtraction of the $\mathrm{CH}_{4}$ term in the HP equation. Therefore, the difference in HP cannot be explained by differences due to heat pro- 


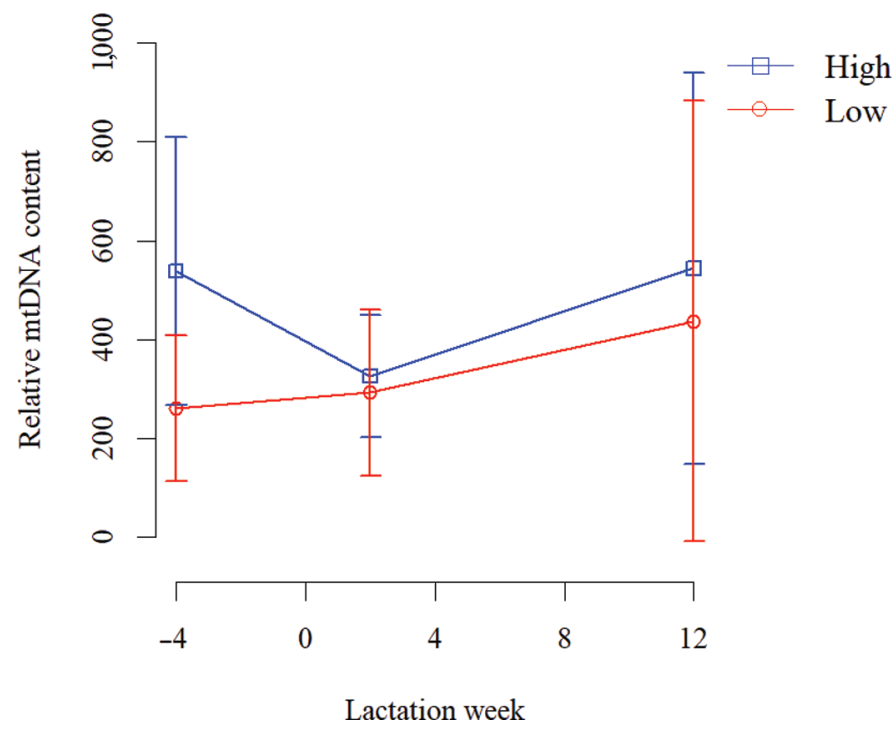

Figure 2. The relative mitochondrial DNA (mtDNA) content in the liver of dairy cows grouped by either high (blue) or low (red) feed efficiency (ECM/DMI). Samples were measured at $-4(\mathrm{n}=9), 2(\mathrm{n}=$ $8)$, and $12(\mathrm{n}=10)$ wk relative to parturition. $P$-values: group $(0.04)$, week (0.67), and group by week interaction (0.67). Data were transformed using the natural log for statistical analysis, and the mean of the observed data \pm SD is shown for interpretation.

duced from rumen fermentation. Although we observed a difference in $\mathrm{CH}_{4}$ produced, when corrected for DMI during the AD-LIB period, the yield of $\mathrm{CH}_{4}$ did not differ between groups, similarly to the findings of Olijhoek et al. (2018), who reported no difference in $\mathrm{CH}_{4} / \mathrm{DMI}$ in dairy cows grouped by RFI when RFI was treated as a class factor in the statistical model. Nkrumah et al. (2006) also observed that $\mathrm{CH}_{4}$ production was lower in low-RFI compared with high-RFI cattle, despite a lack of differences in $\mathrm{DMI} / \mathrm{kg}$ of $\mathrm{BW}^{0.75}$. Conversely, Olijhoek et al. (2018) also reported that, when RFI was treated as a continuous factor in the statistical model, low-RFI cows produced more $\mathrm{CH}_{4} / \mathrm{DMI}$ than
high-RFI cows. The lower methane intensity $\left(\mathrm{CH}_{4} / \mathrm{kg}\right.$ of milk yield) in $\mathrm{H}$ than $\mathrm{L}$ was likely driven by the differences in $\mathrm{CH}_{4}$ production and numerical difference in milk yield. Guinguina et al. (2020) similarly reported a lower methane intensity $\left(\mathrm{CH}_{4} / \mathrm{ECM}\right)$ for more efficient dairy cows compared with inefficient cows, whereas Olijhoek et al. (2018) reported no difference in methane intensity between RFI groups. The higher $\mathrm{CH}_{4}$ production of L cows during the RES period likely resulted from the numerically higher feed consumed during the AD-LIB period, which had not yet passed through the rumen and continued to be fermented. This is supported by an exponential decline in $\mathrm{CH}_{4}$ production over the RES period (Supplemental Figure S1, https: //dataverse.harvard.edu/dataset.xhtml? persistentId= doi:10.7910/DVN/S24HKB). However, because we observed no differences in $\mathrm{CH}_{4} / \mathrm{DMI}$ during the AD-LIB period, $\mathrm{CH}_{4}$ likely does not contribute to differences in feed efficiency between groups in our study.

Major contributors to HP include COX and FOX, which can be estimated through indirect calorimetry. In our study, COX and FOX accounted for approximately $91 \%$ of calculated HP during the AD-LIB period and $83 \%$ during the RES period. Although we observed no difference in COX, as hypothesized, FOX and FOX/ $\mathrm{mBW}$ were higher in $\mathrm{L}$ compared with $\mathrm{H}$ during the AD-LIB period. The tendency for average RQ to be lower in $\mathrm{L}$ than $\mathrm{H}$ during the $\mathrm{AD}-\mathrm{LIB}$ period further supports that FOX is greater in L compared with $\mathrm{H}$. Additionally, a tendency for a difference was noted when FOX was adjusted for DMI, which further supports that the difference in FOX may be innate and not solely driven by feed consumption. However, FOX and COX are influenced by DMI, and, although no significant difference was detected, L had a numerically larger estimated decrease in DMI during the RC compared with $\mathrm{H}$, which may have contributed to the noted increase in FOX in the L group compared with $\mathrm{H}$. We

Table 5. Student $t$-tests of different production and metabolic traits during the respiration chamber period in second-lactation dairy cows grouped by either high or low feed efficiency (ECM/DMI) ${ }^{1}$

\begin{tabular}{|c|c|c|c|}
\hline Parameter $^{2}$ & High & Low & $P$-value \\
\hline \multicolumn{4}{|c|}{ Calculated for ad libitum feeding period } \\
\hline COX/DMI, g/kg & $293^{(270,316)}$ & $256^{(202,309)}$ & 0.13 \\
\hline FOX/DMI, g/kg & $59.9^{(39.1,80.8)}$ & $88.3^{(54.1,122)}$ & 0.09 \\
\hline Heat production/DMI, MJ/kg & $7.86^{(7.25,8.47)}$ & $8.39^{(7.37,9.42)}$ & 0.26 \\
\hline $\mathrm{CH}_{4} / \mathrm{DMI}, \mathrm{L} / \mathrm{kg}$ & $28.2^{(23.9,32.4)}$ & $31.3^{(27.6,35.1)}$ & 0.16 \\
\hline \multicolumn{4}{|c|}{ Estimated for respiration chamber period ${ }^{3}$} \\
\hline $\mathrm{ECM}, \mathrm{kg}$ & $42.7^{(34.8,50.6)}$ & $39.8^{(32.3,47.4)}$ & 0.49 \\
\hline ECM, $\mathrm{g} / \mathrm{kg}$ of $\mathrm{BW}^{0.75}$ & $354^{(291,417)}$ & $304^{(273,336)}$ & 0.10 \\
\hline $\mathrm{BCS}$ & $2.45^{(1.93,2.98)}$ & $2.95^{(2.30,3.60)}$ & 0.14 \\
\hline $\mathrm{BFT}, \mathrm{cm}$ & $1.11^{(0.89,1.34)}$ & $1.14^{(0.73,1.54)}$ & 0.89 \\
\hline
\end{tabular}

${ }^{1}$ Values presented as mean ${ }^{(95 \% \mathrm{CI})}$.

${ }^{2} \mathrm{COX}=$ carbohydrate oxidation; FOX $=$ fatty acid oxidation; BFT = back fat thickness.

${ }^{3}$ Estimates based on averaging values \pm 1 wk relative to the respiration chamber period for each cow. 
Table 6. Weekly effects of select plasma metabolites and effects of BCS and back fat thickness (BFT) during the transition period (wk -3 to 3 ) in second-lactation dairy cows grouped by either high or low feed efficiency (ECM/DMI) ${ }^{1}$

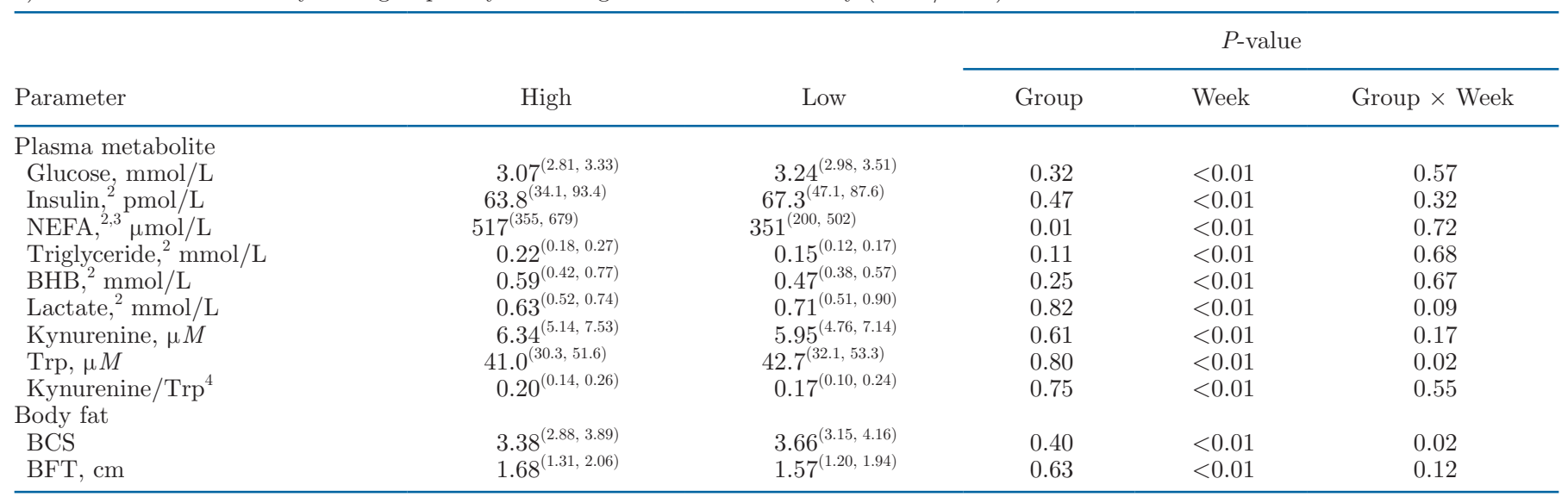

${ }^{1}$ Values presented as $\operatorname{LSM}^{(95 \% \mathrm{CI})}$ unless otherwise noted.

${ }^{2}$ Data natural log-transformed for statistical analysis, and mean of observed data ${ }^{(95 \% \mathrm{CI})}$ reported for interpretation.

${ }^{3} \mathrm{NEFA}=$ nonesterified fatty acids.

${ }^{4}$ Data transformed using the reciprocal for statistical analysis, and mean of observed data ${ }^{(95 \% \mathrm{CI})}$ reported for interpretation.

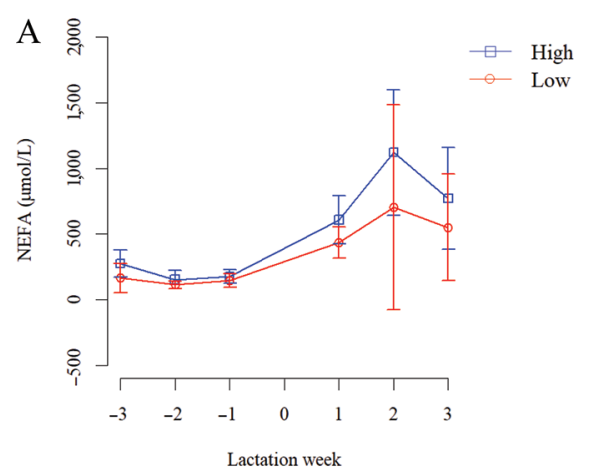

$\mathrm{D}$

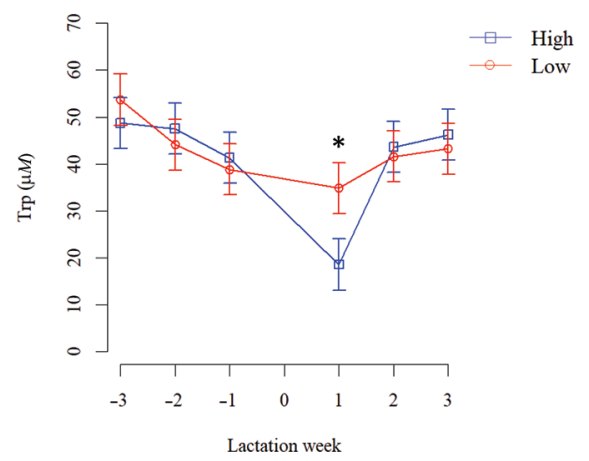

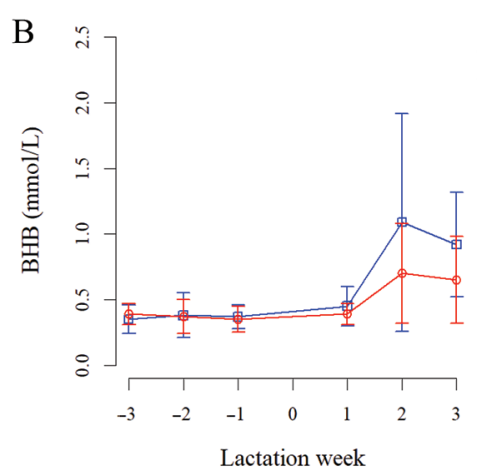

$\mathrm{E}$

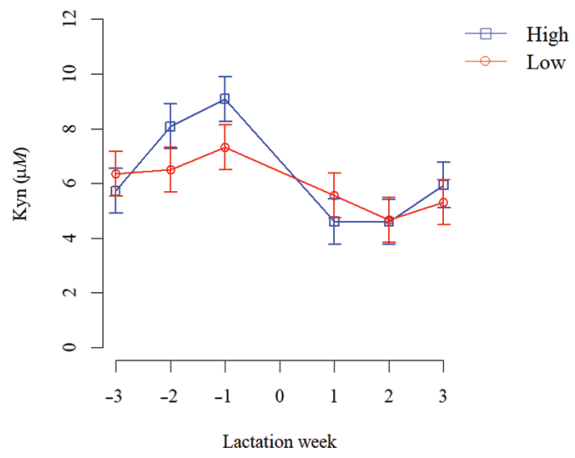

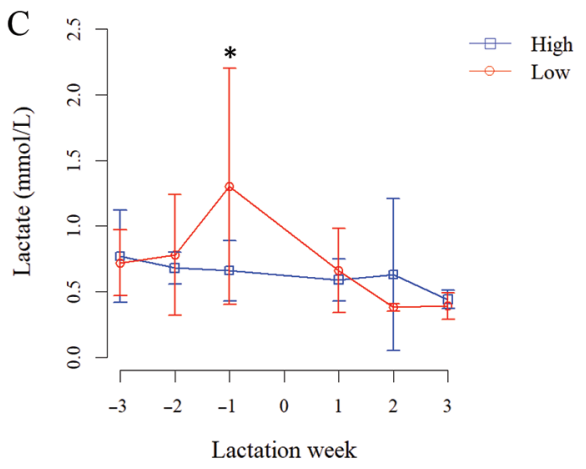

$\mathrm{F}$

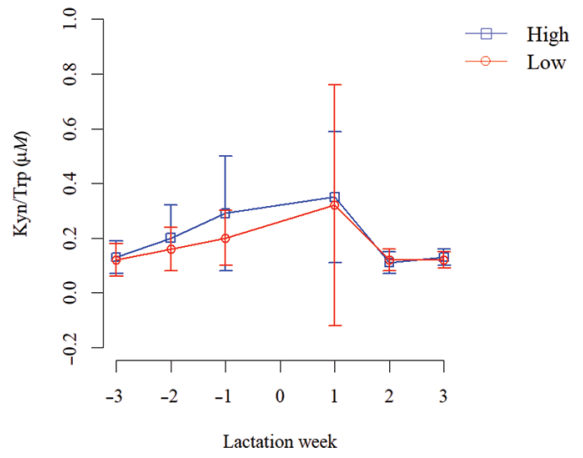

Figure 3. The weekly plasma concentration of (A) nonesterified fatty acids (NEFA; $\mu \mathrm{mol} / \mathrm{L}),(\mathrm{B}) \mathrm{BHB}(\mathrm{mmol} / \mathrm{L}),(\mathrm{C})$ lactate $(\mathrm{mmol} / \mathrm{L})$, (D) $\operatorname{Trp}(\mu M),(\mathrm{E})$ kynurenine $(\mathrm{Kyn} ; \mu M)$, and $(\mathrm{F})$ the Kyn/Trp ratio during the transition period in second-lactation dairy cows grouped by either high (blue) or low (red) feed efficiency (ECM/DMI). Samples were analyzed from wk -3 through 3 postpartum. An asterisk indicates significant differences between groups at a time point $(P \leq 0.05)$. $P$-values for NEFA, BHB, lactate, Trp, Kyn, and Kyn/Trp are given in Table 6. Error bars indicate SEM unless otherwise noted. The plasma concentrations of NEFA, BHB, and lactate were transformed using the natural $\log$ for statistical analysis, and the mean of the observed data \pm SD is shown for interpretation. The Kyn/Trp ratio was transformed using the reciprocal for statistical analysis, and the mean of the observed data $\pm \mathrm{SD}$ is shown for interpretation. 
did not detect significant differences in FOX between groups during the RES period, potentially because a maximum rate of FOX was reached during feed withdrawal, suggesting that both groups of cows possess a similar capacity for fat oxidation. Although COX/FOX was higher for $\mathrm{H}$ than $\mathrm{L}$ during the $\mathrm{AD}-\mathrm{LIB}$ period,
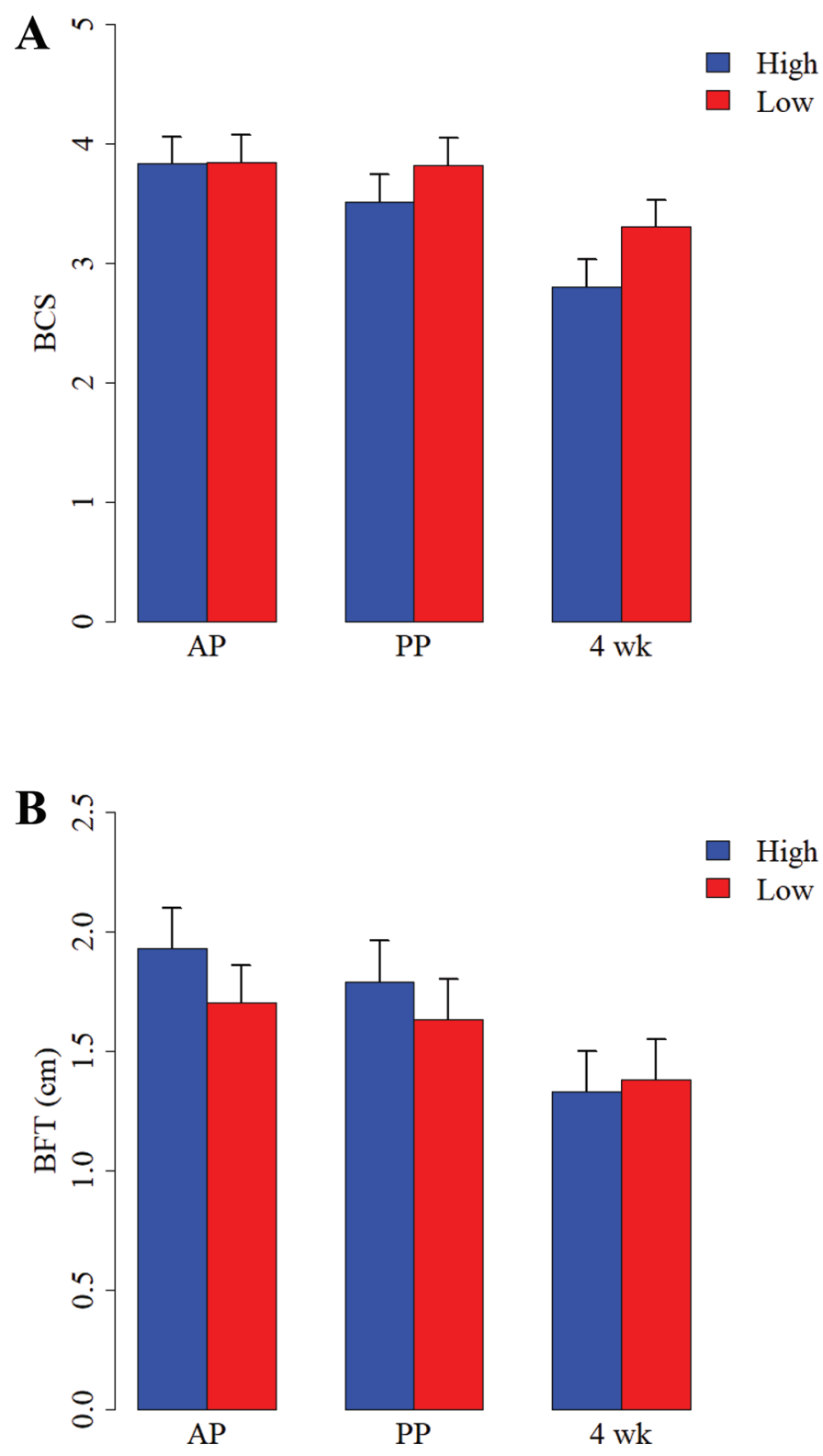

Figure 4. The BCS (A) and back fat thickness (BFT; B) of dairy cows grouped by either high (blue) or low (red) feed efficiency (ECM/ $\mathrm{DMI}$ ). The antepartum (AP; -6 to -1 wk relative to parturition) and immediate postpartum (PP; 0 to 3 wk relative to parturition) periods were determined by averaging the BCS and BFT measurements during those periods. $P$-values for BCS: group $(0.40)$, week $(<0.01)$, and group by week interaction (0.02). $P$-values for BFT: group (0.63), week $(<0.01)$, and group by week interaction (0.12). Error bars indicate upper $95 \%$ confidence limits. these differences are likely driven by FOX, because we did not detect differences in COX. Furthermore, the tendency for a difference in COX/HP between $\mathrm{H}$ and $\mathrm{L}$ during the AD-LIB period is likely driven by the difference in HP.

Although FOX was shown to be directly related to BW and adipose stores (Börner et al., 2013), we detected no difference in BFT, BW, nor BCS during the RC period. Plasma NEFA concentration also did not differ between groups during the RC period, suggesting that adipose tissue mobilization was comparable during the RC period, as intended by the experimental design. Therefore, our data suggest that the difference in FOX between $\mathrm{H}$ and $\mathrm{L}$ observed during the $\mathrm{RC}$ period may result from an intrinsic difference. However, much research would be needed to substantiate this claim, and we are unable to propose a mechanism from the current data. Regardless, greater HP at comparable BW, milk yield, and DMI is correlated with less efficiency. Because animals were not housed in RC during the transition period and we did not measure recovery of BCS throughout lactation, an important aspect related to efficiency, we caution that our results may be applicable only during early lactation, excluding the transition period, and further research is needed to examine whether FOX and HP differ throughout all stages of lactation. By housing dairy cows in RC and measuring BCS at multiple points throughout lactation, the dynamics of fat mobilization during early lactation and accretion during late lactation could be deduced as well as the consistency of feed efficiency within a lactation cycle.

Unexpectedly, we observed no differences in plasma metabolite concentrations between the groups during the RC period, including plasma insulin, NEFA, BHB, and triglyceride concentrations, which are metabolites typically associated with fatty acid metabolism. Additionally, we detected no difference in insulin sensitivity between groups. Yet, these results support our observation of no difference in BW, BCS, BFT, and energy balance between groups during the RC period. Previously, Nascimento et al. (2015) and Kelly et al. (2011) reported that higher-RFI cattle (i.e., less efficient animals) had lower plasma insulin concentrations compared with low-RFI animals (i.e., more efficient animals). However, Kelly et al. (2011) noted no differences in plasma glucose, BHB, or NEFA concentrations, and Nascimento et al. (2015) reported no differences in plasma glucose, triglycerides, or AST concentrations, similar to our results. On the contrary, Bonilha et al. (2017) reported no differences in plasma NEFA or insulin concentrations between high- and low-RFI beef bulls. Given the contradictory results in the literature and our own results, it appears that a reliable plasma 
biomarker for differences between low and high feedefficient animals has not yet been identified.

Because indirect calorimetry does not account for formation of intermediates or cycling of metabolic pathways (Derno et al., 2013), we are not able to attribute FOX and COX to individual tissues, nor accurately determine the effects of anaerobic metabolism. Despite these limitations, previous literature has suggested that the transport and metabolism of lipids may differ between high- and low-RFI beef cattle and that less efficient animals potentially undergo increased oxidative stress (Alexandre et al., 2015; Tizioto et al., 2015; Fonseca et al., 2019). Additionally, differences or tendency for differences in coupling of oxidative phosphorylation and respiration have been noted in the mitochondria of liver and muscle tissue of RFI-grouped animals, with low-RFI animals typically having a higher respiration control ratio compared with high-RFI animals, suggesting that low-RFI animals have a greater efficiency of electron transfer (Kolath et al., 2006a; Lancaster et al., 2014; Fernandez et al., 2020). Given that we noted a lower mtDNA copy number for L, yet a higher HP, compared with $\mathrm{H}$, these results suggest that $\mathrm{H}$ potentially has a higher oxidative phosphorylation efficiency compared with L. Furthermore, Fonseca et al. (2015) and Tizioto et al. (2015) observed a higher relative expression of uncoupling protein 2 (UCP2) in the liver of low-RFI beef cattle compared with high-RFI cattle. Because UCP2 is housed in the mitochondria, a difference in its expression could result from differences in mitochondrial content, which aligns with our own results, as we detected a greater relative mitochondrial content in $\mathrm{H}$ compared with L. However, a recent study by Baldassini et al. (2018b) did not detect a difference in mitochondrial content between RFI groups in liver, muscle, or adipose tissue of beef bulls. McKenna et al. (2020) also reported no difference in mitochondrial abundance in muscle or liver in beef bulls, using citrate synthase as a marker. Despite the contradictory literature regarding the role of mitochondrial function and abundance in efficiency, recent genomic and proteomic studies continue to suggest that mitochondrial function affects RFI and, hence, feed efficiency (Baldassini et al., 2018a; Li et al., 2019). Furthermore, the mitochondrial content did not significantly change over time, indicating that this biomarker could be applied to dairy cows independent of their physiological status.

Various intermediates of the Trp degradation pathways, including Kyn, are involved in $\mathrm{NAD}^{+}$synthesis, and a high plasma Kyn/Trp ratio reflects insufficient mitochondrial activity and ATP production (Lindquist et al., 2020). Although we observed lower Trp concentration for $\mathrm{H}$ compared with $\mathrm{L}$ at wk $1 \mathrm{PP}$, the Kyn/Trp ratio did not differ between groups in our study, presuming that mitochondrial activity and ATP production efficiency would be not different between groups. However, the abundance of mitochondria per cell in the liver was lower, whereas whole-body HP was higher in L, suggesting less mitochondrial ATP production efficiency in L. Additionally, Ghaffari et al. (2019) reported a decrease in serum Kyn during wk 1 PP, but the Kyn/Trp ratio did not differ between normal- and high-conditioned cows. This and our results suggest that the plasma Kyn/Trp ratio is not a suitable marker to assess mitochondrial energy production efficiency in the liver of dairy cows.

Other factors that may affect efficiency include organ and tissue size, because larger organ size requires a greater amount of energy for maintenance (Smith and Baldwin, 1974; Basarab et al., 2003). Basarab et al. (2003) reported that higher feed-efficient steers had lighter liver, stomach, and intestine weights than lower feed-efficient steers. However, we did not measure organ size in our experiment, so we are unable to determine whether differences are present and to what extent they may or may not be contributing to maintenance requirements. Nevertheless, differences in liver mass could affect FOX measurements because the liver, estimated to account for up to $25 \%$ of total energy expenditure in lactating dairy cows (Smith and Baldwin, 1974), primarily relies on fatty acids as its fuel for oxidation. Additionally, tissue composition may be an important factor as well. Basarab et al. (2003) observed that that low-RFI steers tended to have less carcass intramuscular fat than high-RFI steers. Therefore, differences in body composition, specifically in regard to adipose tissue and skeletal muscle, could partially explain the difference noted in FOX between our groups.

In summary, through the use of indirect calorimetry, we were able to identify differences in HP and FOX between high and low feed-efficient groups at wk 5.7 PP. Although other studies have suggested that fatty acid metabolism was a potential factor influencing differences in feed efficiency, our study shows direct support that net FOX is likely contributing to the higher HP observed in less efficient dairy cows. Yet, many factors could potentially have caused the difference in FOX, and, as previously mentioned, we are unable to determine specific mechanisms or identify the tissues principally responsible for the observed differences in FOX. Therefore, further research is needed to examine potential underlying mechanisms that may be contributing to the observed difference in FOX, with continued focus on liver tissue and skeletal tissue, as well as organ systems that rely primarily on fatty acids or ketones as a fuel for oxidation. Additional research should also examine whether the noted differences in FOX and HP for animals grouped by ECM/DMI are 
constant throughout lactation, particularly during the transition period, when lipid mobilization is increased.

\section{CONCLUSIONS}

The results from our preliminary study demonstrate a difference in metabolic fuel oxidation between high and low feed-efficient animals, in that low feed-efficient cows have a higher fat oxidation during ad libitum feeding than high feed-efficient cows at approximately wk 6 postpartum. We also detected higher heat production and methane production in low feed-efficient animals. Although no differences in DMI, BW, or milk yield were detected while the dairy cows were housed in the respiration chamber, our results suggest that lower feed efficiency may result from fewer mitochondria per liver cell and greater heat production losses, and that higher fat oxidation likely contributes to the higher heat production.

\section{ACKNOWLEDGMENTS}

We thank the staff of the Experimental Animal Facility for Cattle and the Animal Technical Center for assistance with animal handling and respiration chamber experiments, as well as H. Pröhl, B. Wego, R. Fürstenberg, S. Görs, K. Karparti, and F. Koch for their help in sample preparation and analyses (all of the Leibniz Institute for Farm Animal Biology, Dummerstorf, Germany). This work was financially supported by the core budget of the Leibniz Institute for Farm Animal Biology (FBN). Data are stored at FBN and are available upon request. The authors declare no conflict of interest.

\section{REFERENCES}

Alemu, A. W., D. Vyas, G. Manafiazar, J. A. Basarab, and K. A. Beauchemin. 2017. Enteric methane emissions from low- and high-residual feed intake beef heifers measured using greenfeed and respiration chamber techniques. J. Anim. Sci. 95:3727-3737. https://doi.org/10.2527/jas.2017.1501.

Alexandre, P. A., L. J. Kogelman, M. H. Santana, D. Passarelli, L. H. Pulz, P. Fantinato-Neto, S. L. Silva, P. R. Leme, R. F. Strefezzi, L. L. Coutinho, J. B. S. Ferraz, J. P. Eler, H. N. Kadarmideen, and H. Fukumasu. 2015. Liver transcriptomic networks reveal main biological processes associated with feed efficiency in beef cattle. BMC Genomics 16:1073. https://doi.org/10.1186/s12864-015-2292 -8 .

Baldassini, W. A., S. F. M. Bonilha, R. H. Branco, J. C. S. Vieira, P. M. Padilha, and D. P. D. Lanna. 2018a. Proteomic investigation of liver from beef cattle (Bos indicus) divergently ranked on residual feed intake. Mol. Biol. Rep. 45:2765-2773. https://doi.org/ 10.1007/s11033-018-4341-2.

Baldassini, W. A., J. J. Ramsey, R. H. Branco, S. F. M. Bonilha, M. R. Chiaratti, A. S. Chaves, and D. P. D. Lanna. 2018b. Estimated heat production, blood parameters and mitochondrial DNA copy number of Nellore bulls (Bos indicus) with high and low residual feed intake. Livest. Sci. 217:140-147. https://doi.org/10.1016/j .livsci.2018.10.004.

Basarab, J., M. Price, J. Aalhus, E. Okine, W. Snelling, and K. Lyle. 2003. Residual feed intake and body composition in young growing cattle. Can. J. Anim. Sci. 83:189-204. https://doi.org/10.4141/ A02-065.

Bauman, D. E., S. N. McCutcheon, W. D. Steinhour, P. J. Eppard, and S. J. Sechen. 1985. Sources of variation and prospects for improvement of productive efficiency in the dairy cow: A review. J. Anim. Sci. 60:538-592.

Boguhn, J., H. Kluth, O. Steinhöfel, M. Peterhänsel, and M. Rodehutscord. 2003. Nutrient digestibility and prediction of metabolizable energy in total mixed rations for ruminants. Arch. Tierernahr. 57:253-266. https://doi.org/10.1080/00039420310001594405.

Bonilha, S. F. M., R. H. Branco, M. E. Z. Mercadante, J. N. dos Santos Gonçalves Cyrillo, F. M. Monteiro, and E. G. Ribeiro. 2017. Digestion and metabolism of low and high residual feed intake Nellore bulls. Trop. Anim. Health Prod. 49:529-535. https://doi .org/10.1007/s11250-017-1224-9.

Börner, S., E. Albrecht, C. Schäff, S. Hacke, U. Kautzsch, M. Derno, H. M. Hammon, M. Röntgen, H. Sauerwein, and B. Kuhla. 2013. Reduced AgRP activation in the hypothalamus of cows with high extent of fat mobilization after parturition. Gen. Comp. Endocrinol. 193:167-177. https://doi.org/10.1016/j.ygcen.2013.08.002.

Brouwer, E. 1965. Report of sub-committee on constants and factors. Pages 441-443 in Proc. 3rd symposium on energy metabolism of farm animals. EEAP.

Cantalapiedra-Hijar, G., M. Abo-Ismail, G. Carstens, L. Guan, R. Hegarty, D. A. Kenny, M. Mcgee, G. Plastow, A. Relling, and I. Ortigues-Marty. 2018. Biological determinants of between-animal variation in feed efficiency of growing beef cattle. Animal 12:s321s335. https://doi.org/10.1017/S1751731118001489.

Chwalibog, A., K. Jensen, and G. Thorbek. 1996. Oxidation of nutrients in bull calves treated with $\beta$-adrenergic agonists. Arch. Tierernahr. 49:255-261. https://doi.org/10.1080/17450399609381888.

Derno, M., G. Nürnberg, and B. Kuhla. 2019. Characterizing the metabotype and its persistency in lactating Holstein cows: An approach toward metabolic efficiency measures. J. Dairy Sci. 102:6559-6570. https://doi.org/10.3168/jds.2019-16274.

Derno, M., G. Nürnberg, P. Schön, A. Schwarm, M. Röntgen, H. Hammon, C. Metges, R. Bruckmaier, and B. Kuhla. 2013. Short-term feed intake is regulated by macronutrient oxidation in lactating Holstein cows. J. Dairy Sci. 96:971-980. https://doi.org/10.3168/ jds.2012-5727.

Drackley, J. K., S. S. Donkin, and C. K. Reynolds. 2006. Major advances in fundamental dairy cattle nutrition. J. Dairy Sci. 89:13241336. https://doi.org/10.3168/jds.S0022-0302(06)72200-7.

Du, X., T. Shen, H. Wang, X. Qin, D. Xing, Q. Ye, Z. Shi, Z. Fang, Y. Zhu, Y. Yang, Z. Peng, C. Zhao, B. Lv, X. Li, G. Liu, and X. Li. 2018. Adaptations of hepatic lipid metabolism and mitochondria in dairy cows with mild fatty liver. J. Dairy Sci. 101:9544-9558. https://doi.org/10.3168/jds.2018-14546.

Fernandez, E. E., J. W. Oltjen, and R. D. Sainz. 2020. Mitochondrial abundance and function in muscle from beef steers with divergent residual feed intakes. Animal 14:560-565. https://doi.org/10.1017/ S1751731119002209.

Fonseca, L. D., J. P. Eler, M. A. Pereira, A. F. Rosa, P. A. Alexandre, C. T. Moncau, F. Salvato, L. Rosa-Fernandes, G. Palmisano, J B. Ferraz, and H. Fukumasu. 2019. Liver proteomics unravel the metabolic pathways related to feed efficiency in beef cattle. Sci. Rep. 9:5364. https://doi.org/10.1038/s41598-019-41813-x.

Fonseca, L. F. S., D. F. J. Gimenez, M. E. Z. Mercadante, S. F. M. Bonilha, J. A. Ferro, F. Baldi, F. R. P. de Souza, and L. G. de Albuquerque. 2015. Expression of genes related to mitochondrial function in Nellore cattle divergently ranked on residual feed intake. Mol. Biol. Rep. 42:559-565. https://doi.org/10.1007/s11033 -014-3801-6.

Frayn, K. N. 1983. Calculation of substrate oxidation rates in vivo from gaseous exchange. J. Appl. Physiol. 55:628-634. https://doi .org/10.1152/jappl.1983.55.2.628. 
German Society of Nutrition Physiology. 2003. Schätzung der Umsetzbaren Energie (ME) in Mischrationen (TMR) für Wiederkäuer. DLG Verlag.

Ghaffari, M. H., H. Sadri, K. Schuh, G. Dusel, D. Frieten, C. Koch, C. Prehn, J. Adamski, and H. Sauerwein. 2019. Biogenic amines: Concentrations in serum and skeletal muscle from late pregnancy until early lactation in dairy cows with high versus normal body condition score. J. Dairy Sci. 102:6571-6586. https://doi.org/10 $.3168 /$ jds.2018-16034.

Ghaffari, M. H., A. Jahanbekam, C. Post, H. Sadri, K. Schuh, C. Koch, and H. Sauerwein. 2020. Discovery of different metabotypes in overconditioned dairy cows by means of machine learning. J. Dairy Sci. 103:9604-9619. https://doi.org/10.3168/jds.2020-18661.

Gonzalez-Hunt, C. P., J. P. Rooney, I. T. Ryde, C. Anbalagan, R. Joglekar, and J. N. Meyer. 2016. PCR-based analysis of mitochondrial DNA copy number, mitochondrial DNA damage, and nuclear DNA damage. Curr. Protoc. Toxicol. 67:20.11.21-20.11.25. https:/ /doi.org/10.1002/0471140856.tx2011s67.

Guinguina, A., T. Yan, A. R. Bayat, P. Lund, and P. Huhtanen. 2020. The effects of energy metabolism variables on feed efficiency in respiration chamber studies with lactating dairy cows. J. Dairy Sci. 103:7983-7997. https://doi.org/10.3168/jds.2020-18259.

Guyot, H., J. Detilleux, P. Lebreton, C. Garnier, M. Bonvoisin, F. Rollin, and C. Sandersen. 2017. Comparison of various indices of energy metabolism in recumbent and healthy dairy cows. PLoS One 12:e0169716. https://doi.org/10.1371/journal.pone.0169716.

Kelly, A., M. McGee, D. Crews Jr., C. Lynch, A. Wylie, R. Evans, and D. Kenny. 2011. Relationship between body measurements, metabolic hormones, metabolites and residual feed intake in performance tested pedigree beef bulls. Livest. Sci. 135:8-16. https:// doi.org/10.1016/j.livsci.2010.05.018.

Knopp, J. L., L. Holder-Pearson, and J. G. Chase. 2019. Insulin units and conversion factors: A story of truth, boots, and faster halftruths. J. Diabetes Sci. Technol. 13:597-600. https://doi.org/10 $.1177 / 1932296818805074$.

Kolath, W. H., M. S. Kerley, J. W. Golden, and D. H. Keisler. 2006a. The relationship between mitochondrial function and residual feed intake in Angus steers. J. Anim. Sci. 84:861-865. https://doi.org/ 10.2527/2006.844861x.

Kolath, W. H., M. S. Kerley, J. W. Golden, S. A. Shahid, and G. S. Johnson. 2006b. The relationships among mitochondrial uncoupling protein 2 and 3 expression, mitochondrial deoxyribonucleic acid single nucleotide polymorphisms, and residual feed intake in Angus steers. J. Anim. Sci. 84:1761-1766. https://doi.org/10 $.2527 /$ jas.2005-519.

Kuhla, B., M. Kucia, S. Görs, D. Albrecht, M. Langhammer, S. Kuhla, and C. C. Metges. 2010. Effect of a high-protein diet on food intake and liver metabolism during pregnancy, lactation and after weaning in mice. Proteomics 10:2573-2588. https://doi.org/10 $.1002 /$ pmic.200900789.

Lancaster, P. A., G. E. Carstens, J. J. Michal, K. M. Brennan, K. A. Johnson, and M. E. Davis. 2014. Relationships between residual feed intake and hepatic mitochondrial function in growing beef cattle. J. Anim. Sci. 92:3134-3141. https://doi.org/10.2527/jas .2013-7409.

Laubenthal, L., M. Hoelker, J. Frahm, S. Dänicke, K. Gerlach, K.H. Südekum, H. Sauerwein, and S. Häussler. 2016. Mitochondrial DNA copy number and biogenesis in different tissues of early- and late-lactating dairy cows. J. Dairy Sci. 99:1571-1583. https://doi .org/10.3168/jds.2015-9847.

Li, B., L. Fang, D. Null, J. Hutchison, E. Connor, P. VanRaden, M. VandeHaar, R. Tempelman, K. Weigel, and J. Cole. 2019. Highdensity genome-wide association study for residual feed intake in Holstein dairy cattle. J. Dairy Sci. 102:11067-11080. https://doi .org/10.3168/jds.2019-16645.

Lindquist, C., B. Bjørndal, A. Lund, G. Slettom, J. Skorve, O. Nygård, A. Svardal, and R. K. Berge. 2020. Increased fatty acid oxidation and mitochondrial proliferation in liver are associated with increased plasma kynurenine metabolites and nicotinamide levels in normolipidemic and carnitine-depleted rats. Biochim. Biophys. Acta Mol. Cell Biol. Lipids 1865:158543. https://doi.org/10.1016/ j.bbalip.2019.158543.

McKenna, C., R. Porter, C. Fitzsimons, S. Waters, M. McGee, and D. Kenny. 2020. Mitochondrial abundance and function in skeletal muscle and liver from Simmental beef cattle divergent for residual feed intake. Animal 14:1710-1717. https://doi.org/10.1017/ S1751731120000373.

Nascimento, C. F., R. H. Branco, S. F. M. Bonilha, J. N. S. G. Cyrillo, J. A. Negrão, and M. E. Z. Mercadante. 2015. Residual feed intake and blood variables in young Nellore cattle. J. Anim. Sci. 93:1318-1326. https://doi.org/10.2527/jas.2014-8368.

Nkrumah, J. D., E. K. Okine, G. W. Mathison, K. Schmid, C. Li, J. A. Basarab, M. A. Price, Z. Wang, and S. S. Moore. 2006. Relationships of feedlot feed efficiency, performance, and feeding behavior with metabolic rate, methane production, and energy partitioning in beef cattle. J. Anim. Sci. 84:145-153. https://doi.org/10.2527/ 2006.841145x.

Olijhoek, D. W., P. Løvendahl, J. Lassen, A. L. F. Hellwing, J. K. Höglund, M. R. Weisbjerg, S. J. Noel, F. McLean, O. Højberg, and P. Lund. 2018. Methane production, rumen fermentation, and diet digestibility of Holstein and Jersey dairy cows being divergent in residual feed intake and fed at 2 forage-to-concentrate ratios. J. Dairy Sci. 101:9926-9940. https://doi.org/10.3168/jds.2017-14278.

Rischewski, J., A. Bielak, G. Nürnberg, M. Derno, and B. Kuhla. 2017. Rapid Communication: Ranking dairy cows for methane emissions measured using respiration chamber or GreenFeed techniques during early, peak, and late lactation. J. Anim. Sci. 95:3154-3159. https://doi.org/10.2527/jas.2017.1530.

Schröder, U. J., and R. Staufenbiel. 2006. Invited review: Methods to determine body fat reserves in the dairy cow with special regard to ultrasonographic measurement of backfat thickness. J. Dairy Sci. 89:1-14. https://doi.org/10.3168/jds.S0022-0302(06)72064-1.

Sjaunja, L., L. Baevre, L. Junkkarinen, J. Pedersen, and J. Setälä. 1990. A Nordic proposal for an energy corrected milk (ECM) formula. In 27th Session of the International Commission for Recording and Productivity of Milk Animals, Paris, France.

Smith, N., and R. Baldwin. 1974. Effects of breed, pregnancy, and lactation on weight of organs and tissues in dairy cattle. J. Dairy Sci. 57:1055-1060. https://doi.org/10.3168/jds.S0022-0302(74)85008 $-3$.

Stracke, J., W. Otten, A. Tuchscherer, M. Witthahn, C. C. Metges, B. Puppe, and S. Düpjan. 2017. Dietary tryptophan supplementation and affective state in pigs. J. Vet. Behav. 20:82-90. https://doi .org/10.1016/j.jveb.2017.03.009.

Tizioto, P. C., L. L. Coutinho, J. E. Decker, R. D. Schnabel, K. O. Rosa, P. S. Oliveira, M. M. Souza, G. B. Mourão, R. R. Tullio, A. S. Chaves, D. P. D. Lanna, A. Zerlotini-Neto, M. A. Mudadu, J. F. Taylor, and L. C. A. Regitano. 2015. Global liver gene expression differences in Nelore steers with divergent residual feed intake phenotypes. BMC Genomics 16:242. https://doi.org/10.1186/s12864 $-015-1464-\mathrm{x}$.

Weber, C., C. Hametner, A. Tuchscherer, B. Losand, E. Kanitz, W. Otten, S. P. Singh, R. M. Bruckmaier, F. Becker, W. Kanitz, and H. M. Hammon. 2013. Variation in fat mobilization during early lactation differently affects feed intake, body condition, and lipid and glucose metabolism in high-yielding dairy cows. J. Dairy Sci. 96:165-180. https://doi.org/10.3168/jds.2012-5574.

\section{ORCIDS}

K. M. Kennedy ำ https://orcid.org/0000-0003-3382-8376

H. M. Hammon () https://orcid.org/0000-0001-8698-1257

B. Kuhla ๑ https://orcid.org/0000-0002-2032-5502 